\title{
DO COMPETITIVE WORK PLACES DETER FEMALE WORKERS? A LARGE-SCALE NATURAL FIELD EXPERIMENT ON GENDER DIFFERENCES IN JOB-ENTRY DECISIONS
}

\author{
Jeffrey A. Flory \\ Andreas Leibbrandt \\ John A. List \\ Working Paper 16546 \\ http://www.nber.org/papers/w16546 \\ NATIONAL BUREAU OF ECONOMIC RESEARCH \\ 1050 Massachusetts Avenue \\ Cambridge, MA 02138 \\ November 2010
}

We thank the participants at the MOVE 2010 Workshop on gender differences in competitiveness and risk-taking in Barcelona and Dana Ganter and Sean Garborg for their excellent research assistance. The views expressed herein are those of the authors and do not necessarily reflect the views of the National Bureau of Economic Research.

NBER working papers are circulated for discussion and comment purposes. They have not been peerreviewed or been subject to the review by the NBER Board of Directors that accompanies official NBER publications.

(C) 2010 by Jeffrey A. Flory, Andreas Leibbrandt, and John A. List. All rights reserved. Short sections of text, not to exceed two paragraphs, may be quoted without explicit permission provided that full credit, including $\left({ }^{\circ}\right.$ notice, is given to the source. 
Do Competitive Work Places Deter Female Workers? A Large-Scale Natural Field Experiment on Gender Differences in Job-Entry Decisions

Jeffrey A. Flory, Andreas Leibbrandt, and John A. List

NBER Working Paper No. 16546

November 2010

JEL No. C93,J0,J1,J16,K0

\begin{abstract}
Recently an important line of research using laboratory experiments has provided a new potential reason for why we observe gender imbalances in labor markets: men are more competitively inclined than women. Whether, and to what extent, such preferences yield differences in naturally-occurring labor market outcomes remains an open issue. We address this question by exploring job-entry decisions in a natural field experiment where we randomized nearly 7,000 interested job-seekers into different compensation regimes. By varying the role that individual competition plays in setting the wage, we are able to explore whether competition, by itself, can cause differential job entry. The data highlight the power of the compensation regime in that women disproportionately shy away from competitive work settings. Yet, there are important factors that attenuate the gender differences, including whether the job is performed in teams, whether the job task is female-oriented, and the local labor market.
\end{abstract}

Jeffrey A. Flory

University of Maryland

Department of Agricultural

and Resource Economics

College Park, MD 20742

jflory@arec.umd.edu

Andreas Leibbrandt

Department of Economics

University of Chicago

Chicago, IL 60637

leibbrandt@uchicago.edu
John A. List

Department of Economics

University of Chicago

1126 East 59th

Chicago, IL 60637

and NBER

jlist@uchicago.edu 


\section{Introduction}

Whether measured by unemployment rates, wages, or representation at the highest employment levels, persistent gender imbalances exist in labor markets (see, e.g., Goldin, 1990; Altonji and Blank, 1999; Blau and Kahn, 2000; Bertrand and Hallock, 2001). ${ }^{1}$ The intransigence of the observed gender differences is disturbing not only from an equity perspective, but also for its potential impacts on economic growth and even fertility (Galor and Weil, 1996). Several hypotheses have been proposed to explain why such gender inequities exist, with the weight of attention being paid to gender differences in human capital (Blau and Kahn, 2000), discrimination and stereotypes against women (Spencer et al., 1999; Goldin and Rouse, 2000), and expected differences in time taken out of the labor force (List and Rasul, 2010). More recently, an experimental literature has emerged that reports another potential source for the observed gender imbalance: women shy away from competitive workplaces whereas men covet, and even thrive in, competitive environments (Gneezy et al., 2003; Niederle and Vesterlund, 2007).

The empirical foundation for this insight arises from gender and competition laboratory experiments. As a brief background, such experiments typically proceed as follows. First, the experimenter recruits a group of students to participate in an experiment. Second, once situated, the experimenter introduces a task—solving mazes, completing math problems, tossing a ball in a bucket, etc. - and asks each subject to choose their preferred compensation regime. Subjects

\footnotetext{
${ }^{1}$ Blau and Kahn (2000) report that according to one index of occupational segregation by sex, $54 \%$ of all women in the workforce in 1997 would have to change jobs to equalize the occupational distribution of men and women. They note that in 1999, women were still much more concentrated than men in administrative support and service occupations (accounted for by $41 \%$ of the female labor force vs. $15 \%$ that of men). They also report that weekly earnings of female full-time workers, though they rose from $61 \%$ of men's comparable earnings to $76.5 \%$ over 1978 to 1999, appear to have reached a maximum in the mid-1990s at around three-quarter's the amount of male earnings. Bertrand and Hallock (2001) report that among the five highest-paid positions at each of a large sample of US firms, only $2.5 \%$ are women, and that they earn $45 \%$ less than the men.
} 
typically have a choice between either a piece rate or a tournament incentive scheme. For example, under the former, the subject is paid $\$ 1$ per successful attempt. In the latter, the subject is paid \$3 per successful attempt if she outperforms an anonymous partner, and zero otherwise. A stylized result that has emerged from these experiments is that men tend to prefer the competitive environment over the non-competitive environment whereas the opposite is true for women, even in tasks where women are more able. Beyond adding a novel explanation for observed gender imbalances, these simple games provide insights into what might be driving gender differences in naturally-occurring labor markets.

Yet, to date we do not know if such preferences manifest themselves in naturally-occurring settings, and if they do whether there are important economic consequences. This is what our paper offers. Stepping back from the burgeoning literature in laboratory experiments (Gneezy et al., 2003; Gupta et al., 2005; Niederle and Vesterlund, 2007; Gneezy et al., 2009; Balafoutas and Sutter, 2010; Cason et al., 2010, Dohmen and Falk, forthcoming), we advance this line of research in a new direction by analyzing agents in the process of making economic choices in naturally occurring labor markets. In doing so, we are able to examine directly whether the persisting gender gap in labor markets can be at least partly attributed to responses to compensation regimes characterized by varying competition and earnings uncertainty levels, two elements that increasingly distinguish opportunities for professional advancement and entrance to high-level positions (Lemieux et al., 2009).

To test whether men and women are affected differently by reward structures characterized by competition and uncertainty, we conducted a natural field experiment on job-entry decisions 
in sixteen major US cities. ${ }^{2}$ We investigate the extent to which alternative compensation methods affect the proportion of female applicants to actual jobs advertised in different labor markets. We posted employment advertisements to an internet job-board in cities with different market wages and randomized interested job-seekers into different compensation regimes for the same jobs. The set of possible compensation regimes was identical in all cities and job-seekers randomly received treatments either offering fixed-wage compensation, compensation depending mildly on individual relative performance, compensation depending heavily on individual relative performance, team relative performance, or on elements of uncertainty. Thereafter, each job seeker decided whether to formally apply for the position.

In addition, we advertised two different job types. One job ad presented a job task that is more male-oriented, while the other is more female-oriented. Comparing the application patterns for these two job ads renders it possible to clarify the relevance of task-dependence and gendertask associations. In their seminal paper, Akerlof and Kranton (2000) argue that gender-job associations are drivers of gender-specific employment patterns and predict that women sort into employments whose requirements match construed female attributes. Differentiating the position we advertise into a 'male' and 'female' version allows us to explore in the field whether the job task itself, gender associations surrounding the compensation regime, or interactions between these two, affect each gender's response to the contract environment differently.

With 211-690 interested job-seekers per city, a total of 6,779 subjects participated in our experiment. From these job seekers, we find some intriguing data patterns. First, we find as the

\footnotetext{
${ }^{2}$ By "natural field experiment," we refer to the definition articulated in Harrison and List (2004): an experiment with a non-standard subject pool (i.e. not students), with field context in the task and information set, and where the subjects are naturally undertaking the tasks as part of their normal economic goings-on without knowing they are in an experiment. Much of the discussion on laboratory experiments can be equally applied to artefactual field experiments (Harrison and List), also sometimes referred to as "lab-in-the-field" experiments.
} 
compensation package becomes more heavily reliant on individual relative performance, the applicant pool shifts to be more male dominated. In the limit, the gender gap in applications more than doubles when a large fraction of the wage (50\%) depends on relative performance. This data pattern is remarkably consistent with the literature using laboratory experiments. Yet, a surprising finding is that this result is not driven by men preferring competitive environments and women not; rather, we observe that both men and women prefer not to be in competitive environments, but that women simply have stronger preferences against them.

Second, we explore several boundary conditions for our main result. For example, gender differences in the preference for compensation packages that rely on relative performance are attenuated by several factors: whether the task is female-oriented, if the compensation scheme is only mildly based on individual relative performance, and the task is completed in teams. These factors all lead to small and inconsequential gender differences. Likewise, we find a link between gender-based differences in competitiveness and the broader economic environment. In particular, we find that the gender gap in applications for competitive workplaces is correlated with prevailing market wages: the gender gap is most prominent in areas with higher local wages. Simply put, women are more likely to walk away from competitive workplaces if there are good outside options - i.e., positions with comparatively high fixed-wages - but not if these outside options are lacking.

Finally, in a complementary experimental treatment, we find that uncertainty in wages alone cannot induce the gender gap in applications observed in the competition treatments. More specifically, when job seekers face a prospective job that has wage uncertainty, both men and women are equally dissuaded from applying. 
The remainder of the paper is organized as follows. Section 2 describes the design of the experiment. Section 3 analyzes the results. Section 4 finishes with a discussion.

\section{Experimental Design}

To investigate gender differences in job-entry decisions, we conduct a natural field experiment using a $2 \times 6 \times 2$ design in which we vary the employment advertisement, compensation scheme, and application procedure. The design, presented in Figure 1, allows us to isolate the impact of the contract environment on the proportion of initially interested individuals who ultimately apply. Knowing the proportion of interested job-seekers of each gender that remain interested upon learning the salary regime requires knowing not only the number of final applicants, but also the number of initially interested. We therefore employ a two-stage experimental method.

As Figure 1 shows, first, we advertise the position, without reference to the compensation scheme. Then, only after a job-seeker expresses interest in applying, we inform the individual of the compensation scheme, and record whether he or she chooses to apply for the position. ${ }^{3}$ This method also allows us to cleanly randomize across subjects within each city and within the same time period, in a manner that leaves the normalcy of the field setting undisturbed. It furthermore

\footnotetext{
${ }^{3}$ A simpler approach might have been to post employment ads which included the compensation regime at the outset, then simply compare the ratio of male to female applicants across treatments. However, unable to post differing salary regimes for the same job in the same city at the same time, we would have been forced to either vary the salary regime across cities or post different salary regimes for the same job sequentially within the same city, allowing for potential temporal and spatial confounds. In addition, through this method, we would only observe jobseekers who decide to apply after already knowing the salary scheme; the number of job-seekers who would have been interested in the position without knowing the compensation scheme would remain unknown. Inferences based on changes in absolute numbers of final applicants are much more limited. For example, using just the male/female application ratio without knowing the underlying gender ratio of those interested prior to knowing the compensation scheme is highly problematic for a variety of reasons.
} 
allows us to gather individual characteristics even on those subjects who expressed interest but chose not to apply after they were informed about the compensation scheme.

We posted the job ads in a total of sixteen major US metropolitan areas. ${ }^{4}$ The cities were selected with the twin goals of representing a variety of geographical regions of the US which are characterized by different market wages and maximizing the pool of job-seekers from each area (all cities from which we sampled are among the top 25 most populous cities in the country). The order of the ads was posted randomly across cities from January-April of 2010. Ads were posted on one of the most highly-frequented internet job boards in the country, and were always specific to a given city where we were seeking applicants. Communication with subjects was through email, and every interaction was carefully scripted (see Appendix A). At the end of the experiment, we extended job offers in every city and for each position we created. To date, 19 applicants have been hired.

\subsection{The employment advertisements and application procedures}

The postings advertised openings for a position as an administrative assistant, the most common occupation in the US. ${ }^{5}$ We used two different versions - one ad that was for a "masculine" version of the job, the other for a more "feminine" version. The advertisements

\footnotetext{
${ }^{4}$ The internet job-boards are city-specific. The 16 cities included in our study are Atlanta, Boston, Chicago, Washington DC, Dallas, Denver, Houston, Los Angeles, Miami, New York, Philadelphia, Phoenix, Portland, San Diego, San Francisco, and Seattle.

${ }^{5}$ In 2008 and 2009, office and administrative support jobs were the most common type of position to hold, accounting for over 13\% of the workforce each year (Bureau of Labor Statistics Employment and Earnings, January 2010, Vol. 57(1). Available online: http://www.bls.gov/opub/ee/empearn201001.pdf). In addition to being the most common job, an office support position is also very convenient for a natural field experiment. It is fairly simple to create administrative tasks for a subject hired into the position, and it is also quite amenable to setting up remote tasks that can be performed with an internet connection from different locations. One drawback to using office jobs is that they are disproportionately occupied by women. In $2009,6.3 \%$ of the male labor force and $20.4 \%$ of the female labor force held office and administrative support occupations (Ibid.). In 2001, 79\% of administrative support and clerical positions were occupied by women (Gabriel and Schmidtz, "Gender Differences in Occupational Distributions Among Workers," Monthly Labor Review, June 2007, Vol. 130(6), Bureau of Labor Statistics.)
} 
were written to mirror closely other want-ads for similar positions. Each was posted in the “admin/office jobs" section of the jobs website, and had three short paragraphs (see also Appendix A). The first identified who we were, where we were located, and said that we were looking for an administrative assistant in their area to help with a project. ${ }^{6}$ The second paragraph detailed the tasks for the position (preparing short reports based on news stories, and other typical secretarial and office/clerical skills). The third was a single sentence requesting that those who are interested should email their CV or resume. Requesting the job-seekers' resumes before we inform them of the compensation scheme is not unusual on online job boards, and was necessary in order to gather agent characteristics on the full sample of subjects. The advertisement finished with a sign-off from a current employee of our organization, followed by a few brief generalities.

Our male-oriented job-advertisement describes tasks focused around sports. The "female" ad is isomorphic to the "male" ad, but that its focus is general instead. ${ }^{7}$ The text of the two ads is identical, except for minor adjustments aimed to influence the gender distribution of interested job-seekers. The posting title for the male-oriented ad reads "Seeking Sports News Assistant" and mentions a variety of pro-, semi-pro-, and college sports; while that for the female-oriented ad mentions nothing about sports. In both ads, the primary task described was to create news digests by reading local stories and preparing short reports, in addition to other general clerical duties.

\footnotetext{
${ }^{6}$ While not all other employers post self-identifying information, many do. We chose to explicitly identify a genuine organization - one with its own web pages, physical address, phone numbers, etc. - to enhance the normalcy of the situation and minimize any risk of suspicion. Having a genuine employee of the organization sign off the email added further insurance, should any job-seekers wish to do a brief internet search to verify the ad's authenticity.

${ }^{7}$ In a pilot, we initially tried advertising a position focused on fashion for the female version of the job, but the result was that almost no males applied to this job. Given that working as an administrative assistant is generally a female-dominated career, we felt the more general version of the ad is by itself likely to be perceived as a more female-oriented task. Indeed, the general version of the ad resulted in a pool of subjects the substantial majority of which were women.
} 
Note that the only mention of compensation in the job advertisement is that the position is paid on an hourly basis. No information is provided at this point about the duration of the position, number of hours, or opportunities for growth. This enables us to capture the broadest possible sample of job-seekers in the area who are interested in secretarial or clerical positions. While some ads do explicitly detail compensation and duration, we verified that it is common for other employers to leave out specifics on hours and salary, so that our ads remained natural.

Within cities, we were careful to post the male- and female-oriented ads within a short enough time frame of each other to avoid any possible temporal-based selection issues. Yet we still spaced them two days apart, intentionally allowing for many other ads to be posted to the job board between them, to ensure job-seekers did not mistakenly believe they were expressing interest in both positions when responding to only one advertisement. We posted each advertisement once in each city - on Monday or Wednesday, approximately 10 am local time randomly alternating whether the male ad or female ad came first.

In addition to varying the gender-framing of the position by using two different ads, we manipulate the application procedure. By asking job-seekers to fill out application questionnaires with varying lengths, we change the requested level of investment in the application. ${ }^{8}$ The application questionnaires were randomized at the city level. In eight cities, job-seekers had to fill out a long questionnaire with four interview questions, while in the other eight cities the questionnaire was short and contained only one question (see Appendix A).

\footnotetext{
${ }^{8}$ Employers often use self-selection devices to sort out better suited applicants (Spence, 1973; Salop and Salop, 1976). We implemented this commonly used device in our experiment by manipulating the effort needed to complete an application.
} 


\subsection{The compensation scheme treatments}

Within each of the two jobs in a given city, we randomized job-seekers who expressed interest in the position into one of six different treatments. The characteristics of the treatments are summarized in Table 1 and the scripts are listed in Appendix A. Subjects were not given the treatment until after they had already expressed interest in the job, and they received the treatment within 24 hours of expressing this interest. The first two treatments use the same compensation scheme, a fixed-wage of $\$ 15$ an hour, but differ in whether the job is done in teams (T1) or alone (T2). These two treatments serve as our primary control group, against which we compare behavior of job-seekers under the alternative compensation schemes.

The next two treatments T3 and T4 consist of individual tournament-based salary regimes. ${ }^{9}$ The difference between the two is that T3 has a relatively low competition-based reward, whereas T4 has a much higher one. We tell the job-seeker she will be matched with another person we are currently hiring into the same position, and that whichever of the two performs better earns a bonus. For the individual tournament-low treatment T3, the base salary is $\$ 13.50$ an hour and the bonus is equivalent to $\$ 3$ an hour. The worker thus earns $\$ 13.50$ an hour or $\$ 16.50$ an hour, depending on how she performs with respect to her co-coworker. For the individual-high treatment T4, the base salary is $\$ 12$ an hour, with a bonus equal to $\$ 6$ an hour for the most productive worker. So the worker earns $\$ 12$ an hour or $\$ 18$ an hour, depending on relative performance. Dividing the individual relative performance pay scheme into a high competition treatment and low competition treatment helps provide a rough measure of the

\footnotetext{
${ }^{9}$ Other employers offering similar jobs on this job board also sometimes use compensation schemes involving bonuses. However, as an added measure to preserve the normalcy of the economic environment, we added language to the non-standard compensation treatments to explain the nature of the contract. For example, we included the sentence, "We have frequent deadlines, and timely quality information from you is important." The intention here was to provide a natural rationale for why we might want to encourage competition among employees. In addition, for the two team treatments (team-hourly, and team-tournament), we added the sentence "As the work is best done in teams, you will be paired with one co-worker."
} 
elasticity of the gender gap in competitiveness, and the sensitivity of each gender's response to different intensities of competition.

The fifth treatment $\mathrm{T} 5$, group-based competition, places two new hires into a team, and makes their compensation contingent on the group's relative performance with respect to another similarly composed team. The base payment $(\$ 12)$ and bonus (\$6) in this compensation scheme are as in T4. We selected the highly competitive incentive for this treatment in order to intensify any effect, and to render possible comparisons to treatment $\mathrm{T} 4$.

The final treatment aims to capture the gender difference in attitudes towards uncertainty over job compensation. We tell subjects their work contributes to the possibility of journal publication; then, we inform them the base salary for the position is $\$ 13.50$ per hour, plus a bonus that translates to $\$ 3$ per hour if their assistance contributes to journal article publications. ${ }^{10}$ Just as in the competition treatments, there is uncertainty over the payment and the worker is allowed to believe she has the ability to influence the outcome through her own labor. In contrast to the competition treatments, however, she is not performing against anyone else.

Note that the mean payoff for all six salary regimes is identical ( $\$ 15$ an hour). The treatments were communicated via emails. All job-seekers expressing interest in the job received an email. All the emails contained exactly the same text, except the few lines describing compensation (see Appendix A). We thanked the job-seeker for their interest in the position, let them know everyone who contacted us about the job was receiving a general initial email from us with basic

\footnotetext{
${ }^{10}$ We were careful to emphasize the clerical role of the position to subjects, and to clarify that they would merely be providing administrative assistance. This was to ensure that job-seekers did not think they were applying for a position where they might be involved in the actual writing of publications. We should note that it is conceivable that the pure uncertainty treatment T6 also introduces an additional meaning to the work that is not present in the other treatments, if subjects in the other treatments did not understand that their work led to the potential publication of articles. However, there is no theoretical reason or empirical evidence we are aware of that would lead us to expect that this marginal adjustment to the meaning of the task should alter the gender distributions-i.e., that there is a gender/task/treatment interaction. Nevertheless, we urge the reader to keep this in mind when interpreting data from treatment $\mathrm{T} 6$.
} 
information, and included the treatment-specific script. At this point, subjects were still unaware of the job's duration and number of hours per week. ${ }^{11}$

\subsection{The response variable and job-seeker characteristics}

The key variable of interest is the individual decision of whether or not to apply, once the compensation method is known. Every individual who contacted us to express interest in the job constitutes a 'subject' in our experiment. In order to actually apply, however, the interested jobseeker had to fill out the interview questionnaire and send it back to us. ${ }^{12}$ We therefore classify all subjects who returned the questionnaire to us as having applied, and those who did not return the questionnaire as having not applied.

Using internet-based job applications presents a minor challenge in determining the gender of subjects, since it cannot be visually observed. In addition, directly asking a subject's gender (i.e. via email) has important legal implications, and might seem unnatural and disrupt the normalcy of the field setting. Further, directly asking for gender could have altered the subject's decision of whether or not to apply.

In order to determine gender, we use each subject's first name and employ a three-tier method. The vast majority of names are assigned gender based on probabilities derived from the

\footnotetext{
${ }^{11}$ They are informed of these details at the time we offer the job, at which point they decide whether to accept it. We were careful in the emails to create an environment open to questions, apologizing for any questions about the job they may have asked to which we have not responded, and welcoming further inquiries. We could not interact with subjects before they received the salary regime information and made their choice about applying for the job without risking heterogeneous treatment. Yet by creating an environment welcome to inquiries, we minimize the possibility that job-seekers feel jilted or ignored, which might have a (gender-dependent) effect on their propensity to apply.

${ }^{12}$ This is made clear in the treatment email describing compensation, where we indicate that returning the questionnaire completes their application. In the rare cases where a subject sent us a second email of interest in the position (i.e. after receiving our email describing the salary regime) without filling out the questionnaire, we emailed them a reminder that their application is not complete until we receive the questionnaire.
} 
Social Security Administration (SSA) database on name popularity by gender and birth year. ${ }^{13}$

For any names which are not included in the SSA database, we use an additional database created by Geoff Peters (available at http://www.gpeters.com/names/baby-names.php) which calculates gender ratios by first name, using the internet to analyze patterns of name-usage for over 100,000 first names. ${ }^{14}$ This second database is also used as an additional check on the SSAbased assignments in cases where the gender ratio derived from the SSA database is too low to confidently assign one gender or the other. Finally, for all names where neither database yields a large enough gender ratio to make a confident assignment, we perform internet searches for gender identifiers of the actual subjects themselves, e.g., by finding the subjects on social networking websites.

The remaining individual characteristics of interest were gathered from the resumes sent to us by the subjects. These include level of education, job experience (i.e., whether job-seeker has already worked as administrative assistant), and age.

\footnotetext{
${ }^{13}$ We use the SSA database to calculate, for each name, a weighted gender probability. The database reports figures on the most common 1,000 names for men and the most common 1,000 names for women born in any given year. We take a given name, proceed to use the number of men and women born each year with that name, and then create a gender ratio for that name in each given year. We then look across multiple years to create a weighted average of this gender ratio. We first restrict our range to birth years 1944-1993, so as to focus on the most likely birth years of our subjects. Then, since information in the CVs suggests the majority of our subjects are between 22 and 30 years old, we assign lower weights to birth years earlier than 1979 and later than 1987. The weights diminish as birthyears move further from those of the 22-30 year-old bracket. We do this for each name that appears in our sample. If the resulting first name-based weighted probability of being female is larger than $50 \%$, we define the subject as a woman. Otherwise, we define the subject as a man. Note that there are very few names for which gender cannot be inferred accurately. For example, in our sample of job-seekers only $0.8 \%$ of the subjects have names with gender ratios less than $2: 1$, and only $4.8 \%$ have a ratio less than $10: 1$.

${ }^{14}$ For names included in both databases, the Gpeters database generates gender ratios very close to the ratios generated by the SSA database ( $\mathrm{r}=0.89, \mathrm{p}<0.0001$, Pearson)
} 


\section{Experimental Results}

We start with a descriptive overview (Section 3.1) and proceed to present the overall application patterns in the compensation scheme treatments (Section 3.2). Thereafter, we examine determinants of the gender-specific application probabilities (Section 3.3). This section concludes with an investigation of gender-specific individual characteristics in the compensation scheme treatments (Section 3.4).

\subsection{Descriptive overview}

In total, we collected data from 6,779 individuals who responded to one of the two job advertisements. The gender from 5,666 individuals (83.6\%) was assigned using the SSA database. The Geoff Peters database was used to assign gender to 506 individuals (7.5\%), and the internet search allowed us to assign gender to 512 individuals (7.6\%). ${ }^{15}$ Table 2 provides detailed information on the number of observations in each cell of our $2 \times 6 \times 2$ design and application probabilities for selected categories. Table 3 provides information about the sixteen cities where the advertisements were placed, including the number of observations and application probabilities in each location. While 4,239 individuals responded to the female ad, 2,540 responded to the male ad. Of these interested job-seekers, 2,702 individuals ultimately applied for one of our jobs - 1,566 for the female and 1,136 for the male advertisement. This represents approximately $40 \%$ of the job seekers in our sample $(33 \%-48 \%$ of the subjects in each city).

\footnotetext{
${ }^{15}$ The application patterns reported in this paper are not subject to the inclusion of the gender identifiers from the Geoff Peters database or the gender identifiers from the internet search. We excluded from the analysis 37 individuals for whom we could not identify gender. There were also 231 individuals who responded to both job advertisements. For these individuals, we only consider their application decision with respect to the job advertisement to which they responded first. Further, we had to exclude 48 individuals due to technical problems during the e-mail exchange.
} 
As expected, the female advertisement attracts a higher proportion of females than the male advertisement. While $53.5 \%$ of the job-seekers who expressed interest in the male advertisement are women, $80.3 \%$ of the job-seekers for the female advertisement are women which represents a significant difference at the $\mathrm{p}<.01$ level using a Fisher's exact test. ${ }^{16}$ The length of the application questionnaire does not significantly affect application probabilities: $40.6 \%$ of the jobseekers apply if the questionnaire is short and 39\% if the questionnaire is long (Fisher's exact test, $\mathrm{p}=0.188$ ). Yet, the questionnaire length does appear to significantly affect application costs. Applicants respond to the long questionnaire with roughly three times the writing output as that for the short questionnaire (long questionnaire applicants use 338 words on average, while short questionnaire applicants use an average of 117 words, T-test, $\mathrm{p}<0.0001)$.

\subsection{Overall application patterns in the compensation scheme treatments}

Figure 2 illustrates the mean overall application probabilities for women and men for each of the six compensation treatments. We first note that, conditional on expressing initial interest in the job, men are in general more likely to apply: the overall application probability for men is 0.484, significantly higher than for women, who apply with a 0.362 probability (Fisher exact test, $\mathrm{p}<0.0001)$. Second, note that the difference between the application probabilities of men and women is most pronounced in the high-competition treatment $\mathrm{T} 4$, where men are $55.5 \%$ more likely to apply than women ( 0.485 for men versus 0.312 for women, Fisher exact test,

\footnotetext{
${ }^{16}$ The proportion of women responding to our ad that removes male-oriented language is very close to the percentage of office support jobs actually occupied by women $-79 \%$ in 2001, according to the Bureau of Labor Statistics. The close parallel between expressed interest and realized outcomes suggests a strong relationship between gender distributions in the workforce and gender distributions among applicants. This underscores the importance of contract-induced changes in application patterns for realized composition of workers in the labor force.
} 
$\mathrm{p}<0.0001)$. In the competition treatment, $\mathrm{T} 3$, in which compensation depends less heavily on relative performance than in T4, men are $36.4 \%$ more likely to apply than women.

In the team competition treatment, $\mathrm{T} 5$, men's application probability is $31.9 \%$ higher, in the uncertainty treatment, T6, it is $32.5 \%$ higher. In the two baseline treatments $\mathrm{T} 1$ (team-fixed) and T2 (individual-fixed), the probability that males apply is $23.1 \%$ and $26.5 \%$ higher than females' probabilities. Appendix B, Figure A, illustrates the application patterns for each city separately. Table 4 shows the application probability for each gender depending on the compensation scheme, job advertisement, and application procedure. These data patterns lead to our first result:

Result 1: Competitive workplaces significantly increase the gender gap in application probabilities, as women's propensity to apply substantially drops relative to that of men.

For further evidence of this result, we consider a Logit regression model in which we regress the application decision on all possible interactions between treatments $\times$ gender. Table 5 reports the results. The regressions control for location fixed effects and the coefficients reported are marginal effects. The reference group for the regressions is composed of women in treatments $\mathrm{T} 1$ and $\mathrm{T} 2$. We pool the two baseline treatments, as the application probabilities and patterns in $\mathrm{T} 1$ and $\mathrm{T} 2$ are very similar, suggesting these two compensation schemes were perceived as virtually the same. ${ }^{17}$ In Appendix, Table A, we provide regression analyses showing that our findings hold if we do not pool data from treatments T1 and T2. Appendix,

\footnotetext{
${ }^{17}$ Recall that the compensation structure is in fact identical across these two treatments. The only difference between $\mathrm{T} 1$ and $\mathrm{T} 2$ was in the framing of the job as individual or teamwork-based.
} 
Table B, includes a robustness check where we control for subjects' education, job experience, and other potential covariates, none of which affect the application patterns.

Table 5 indicates whether the gender gap in application probabilities in treatments T3 through T6 significantly differs from the gender gap in the two fixed-wage baseline treatments under several different specifications. Model 1 uses the full sample from both job advertisements and both types of questionnaires. We find in this model that the coefficient on the interaction T4 $\times$ male is positive, and significant at the $\mathrm{p}=0.064$ level using a two-sided alternative, or $\mathrm{p}=0.032$ using the one-sided alternative suggested by the literature. That is, as we hold everything but the payment regime constant, the amount by which men are more likely to apply than women substantially increases as we move from the baseline to compensation that depends heavily on individual relative performance. Such contracts make women significantly less likely than men to apply. While the average marginal effect of being male on propensity to apply in the fixed-wage treatments T1\&T2 is 0.106 , the effect of being male under T4 increases by 0.07 . That is, T4 widens the gender gap in propensity to apply by almost $70 \%$. We dig a level deeper into the data to find that:

Result 2: This gap is not driven by men opting to compete and women opting not to compete, but rather by a significantly stronger aversion to competitive workplaces among women than among men.

Figure 2 suggests that women and men both prefer non-competitive workplaces, as application probabilities drop for both genders when moving from fixed-wage compensation (T1 \& T2) to compensation depending on relative performance (T3 \& T4). The estimated coefficients 
for the treatment dummies T3-T6 in Table 5 show the changes in women's application probabilities in each of the four treatments T3-T6, as compared to the baseline treatments. Several insights follow.

First, note that all coefficients for the four treatment dummies are significantly negative and range in magnitude from -0.068 (T6) to -0.127 (T5). That is, women are significantly less likely to apply for jobs in which compensation is not fixed. In particular, the probability that women apply in $\mathrm{T} 4$ is 0.117 lower as compared to treatments $\mathrm{T} 1$ and $\mathrm{T} 2$, which represents a $27.3 \%$ drop in application probability.

If we focus on men in treatments $\mathrm{T} 1$ and $\mathrm{T} 2$ as the reference group for the regressions, we see that men are also less likely to apply for jobs in which compensation is not fixed, but that they generally react less strongly than women (see Appendix Table C). Just as for women, men's application probabilities decrease in treatments T3-T6 as compared to the baseline $\mathrm{T} 1 \& \mathrm{~T} 2$, yet the reductions are smaller than for women. In particular, for T4, the estimated average marginal effect suggests an average drop of only $8.8 \%$ in application probability from the baseline $(-0.047, \mathrm{p}=0.130)$.

We thus observe on the one hand that contracts characterized by relative performance-based pay tend to have a dissuasive effect on both genders, while on the other hand that the effect is substantially stronger for women. The gender gap induced by competition-based contracts is thus driven by the fact that women are more deterred from applying by competitive compensation regimes than are men. This suggests a more nuanced mechanism may be at play in naturally occurring labor markets than the stylized result that has emerged from the rich literature in lab experiments, in which men are often observed to be attracted to competition while women shy away from such environments. 


\subsection{Determinants of the gender gap}

In this section, we explore boundary conditions of our main result. This exploration aids in helping us understand the causes of the observed deviations in application probabilities as well as the factors that attenuate and exacerbate the deviations. A first result emerges:

Result 3: Several factors related to the workplace affect the gender gap, including: i) the degree to which compensation depends on relative performance, ii) whether the job is team based, and iii) the nature of the job task.

We observe a substantial attenuation of the effect of competitive workplaces on the gender gap as we lessen the intensity of the competition incentive from 50\% (treatment T4) of the base wage to $22 \%$ (treatment T3). In Table 5, we see that the estimated coefficient on the interaction T3 $\times$ male drops to approximately one-third of the magnitude of the coefficient on $\mathrm{T} 4 \times$ male; although it remains positive, it becomes insignificant at conventional levels (average marginal effect of $0.022, \mathrm{p}=0.555$ ). That is, ceteris paribus, changing the contract from a fixed wage to compensation mildly dependent on individual relative performance has no significant impact on the gender gap in application probabilities.

We also find that adjusting the relative performance contract to make it team-based reduces the gender gap considerably. Table 5 shows that the coefficient on the interaction $\mathrm{T} 5 \times$ male is small in magnitude and insignificant $(\mathrm{p}=0.937)$. Recall that under $\mathrm{T} 5$, the bonus raises the wage from $\$ 12$ to $\$ 18$, just as for $\mathrm{T} 4$, but that in $\mathrm{T} 5$ workers are evaluated on the joint performance of their team. Thus, while the gender gap in application probabilities significantly increases when 
moving from a fixed hourly wage (T1\&T2) to one heavily dependent on individual relative performance (T4), the gap remains constant when moving from a fixed wage to a wage heavily dependent on team relative performance (T5).

To examine whether and how the nature of the job task affects the gender gap induced by relative performance pay, we investigate gender differences in application probabilities for each of the two job advertisements separately. We start with the male job advertisement. Figure 3 replicates Figure 2 but restricts the data summary to the male job advertisement. As before, we observe that among individuals expressing initial interest in the job, men are more likely to ultimately apply than women. This is true across all six treatments: the mean application probability being 0.534 for men and 0.372 for women, a significant difference at the $\mathrm{p}<.01$ level using a Fisher exact test. Yet, note the striking difference of probabilities in T4, compared to the other five treatments. The gender gap is similar in T1, T2, T3, T5, and T6 (0.109-0.172), where the probability that men apply ranges from $32.8 \%$ to $50.8 \%$ higher than that for women. It is considerably more pronounced in $\mathrm{T} 4(0.281$; application probability women $=0.298$, men $=$ 0.579 ), where the probability that men apply is $94 \%$ higher than it is for women. This represents a very strong gender effect in moving from initially interested job-seekers to those who actually apply upon learning the compensation regime. While for every man who signalled interest in the male-oriented job there are 1.13 women who signalled interest, in $\mathrm{T} 4$ there are only 0.58 women that ultimately applied for every man that applied.

Model 2 in Table 5 is identical to Model 1, with the exception that it is restricted to responses for the male job advertisement. Empirical results are qualitatively similar to Model 1, which uses the full sample. The treatment dummies show that women are significantly less likely to apply in T3-T6 as compared to the baseline, and the male dummy indicates that the application 
probability is 0.124 higher for men in the baseline. As in Model 1, all treatment $\times$ gender interactions are insignificant $(\mathrm{p}>0.445)$ besides $\mathrm{T} 4 \times$ male. Note that now, however, the coefficient on $\mathrm{T} 4 \times$ male more than doubles in magnitude and substantially increases in significance. The difference-in-difference in application probabilities in moving from the fixed hourly wages to the strong individual competition treatment is now 0.153 , and significant at the $\mathrm{p}<.01$ level using a two-sided alternative.

Importantly, this result shows that when we restrict the sample to the male job-task and hold everything but the payment regime constant, the gender gap in application probabilities observed in the baseline T1 and T2 (0.124) increases by approximately 125\% when compensation depends heavily on individual relative performance.

Figure 4 is identical to Figure 3, but now shows only the application probabilities for the female job advertisement. We observe again that, conditional on expressing initial interest in the job, men are generally more likely to apply, but that the difference in overall application rates is much smaller than for the male ad (application probability of men $=0.414$, application probability of women $=0.358$; Fisher exact test, $p=0.003$ ). We also see that the gender gap in application probabilities is quite similar across all six treatments. The smallest gender difference is in T4 (0.021) and the largest in T2 (0.072). In none of the six treatments are women significantly less likely to apply than men ( $p>0.107)$.

Model 3 in Table 5 is identical to Model 1, with the exception that it is restricted to responses to the female job advertisement. The results are similar to Models 1 and 2, with one crucial exception. As in Models 1 and 2, the coefficients on the treatment dummies show that women are significantly less likely to apply in treatments T3-T6 as compared to the baseline. Also, the male dummy is significant at conventional levels, suggesting that men who expressed initial 
interest in the advertisement are more likely to apply in the baseline as compared to women. However, turning to the treatment $\times$ gender interactions, we now see that none of the coefficients are significant $(\mathrm{p}>0.525)$. That is, none of the treatments significantly alter the gender gap in propensity to apply among job-seekers interested in the female-oriented position. The $\mathrm{T} 4 \times$ male interaction is now small and insignificant $(\mathrm{p}=0.555)$ : the gender gap in application probabilities caused by the strong competition incentive has vanished for female based jobs.

A closer look at the data reveals that the disappearance of the gender gap in T4 as we move from the male ad to the female ad is driven mostly by a large drop in the fraction of men who ultimately apply, but also partly by an increase in the fraction of women applying. Among men, the application probability is similar when moving from the baseline to T4 under the male ad (estimated change $=0.006, \mathrm{p}=0.879$ ), but it significantly drops (by $0.139 ; \mathrm{p}=0.005$ ) when moving from the baseline to T4 under the female ad. Among women, the application probability decreases by 0.147 when moving from the baseline to treatment $\mathrm{T} 4$ under the male ad, but drops by only 0.104 when moving from the baseline to treatment $\mathrm{T} 4$ under the female ad. That is, while men are largely unaffected and women severely dissuaded by treatment T4 under the male ad, both genders are dissuaded by treatment T4 from applying under the female ad (though women less than under the male ad). Thus, we find that when switching the framing of the job from male- to female-oriented, men switch from being indifferent to strong individual competition to being deterred by it, while women become less deterred by it, causing the gender gap to disappear. Moving to treatment T6, we find a further result: 
Result 4: Uncertainty alone is insufficient to cause the gender gap: wage contracts that impose pure uncertainty on workers' compensation have an equally dissuasive effect on applications from both women and men.

Turning our attention to treatment $\mathrm{T} 6$, we find that when compensation depends purely on uncertain elements, the effect on application probabilities is negative. Recall that in T6, the worker is not in competition with anyone else, but does receive a bonus if a particular outcome occurs. Model 1 of Table 4 shows that the estimated coefficient on the dummy for T6 is -0.068 $(\mathrm{p}=0.001)$. However, the coefficient on the gender-treatment interaction $\mathrm{T} 6 \times$ male is small and insignificant $(\mathrm{p}=0.749)$. That is, we find no evidence of a gender-dependent response to purely uncertain compensation, as the gender gap does not change in moving from the baseline treatments to T6. Holding everything but the contract constant, moving from fixed-wage to uncertain compensation reduces the propensity to apply by an average of $6.8 \%$ for women and $5.6 \%$ for men (Table C).

An additional piece of speculative evidence that speaks to uncertainty as an explanation for the gender gap in competitive workplaces comes from the comparison of T4, where compensation depends heavily on individual relative performance, and T5, where compensation depends heavily on team relative performance. While the variance in potential wages is constant between $\mathrm{T} 4$ and T5, the level of uncertainty is arguably lower in T4 than in T5, as in T4 there is no uncertainty about the performance of the subject's team member. Thus, were uncertainty to be an important driver of the gender gap in T4, we would observe a larger gender gap in T5. However, this is at odds with the actual pattern of the data, which in fact shows no gender gap in T5. 
We are now in a position to move to an analysis of how the economic environment affects application patterns. Placing our employment advertisements in multiple cities enables us to explore the link between: i) the gender-dependent responses to different contract-types we observe in our data; and ii) local labor market conditions. Our subjects come from sixteen different labor markets, all of which differ in their market hourly wages. To obtain precise estimates of prevailing local wages, we collected data on the median hourly wages from comparable administrative assistant jobs posted on the same online job board, for positions which offered fixed-wage compensation. The median wage levels we observe in these data range from $\$ 10$ - $\$ 14$ per hour across the sixteen different cities. While lower than the most recent Bureau of Labor Statistics data on mean compensation for administrative office jobs (ranging in the same cities from $\$ 14.99-\$ 20.03$ in May 2009), the two data sets for wages of jobs comparable to the one we advertised are highly correlated $(\mathrm{r}=0.914, \mathrm{p}<0.0001)$.

There are reasons to expect that local wage levels may affect the gender difference in willingness to enter workplaces where compensation depends on competition and uncertain outcomes. When women have fewer (or less attractive) outside options to work in a job with fixed wages, i.e. when market wages are comparatively low, they may be less reluctant to enter competitive workplaces - even if they dislike competing. This leads us to our next result:

Result 5: Market wages are critically linked to the gender gap: as wages rise towards our offered wage, women are disproportionately deterred from applying to the competitive job.

To provide evidence of this result, we estimate the average marginal effects of the treatment $\times$ gender interactions for each city separately, controlling for job experience, education, and job 
task. We then examine the relationship between these estimated effects and the median wage levels in each location. Figure 5 provides an initial look at this relationship by comparing wage levels to the size of the gender gap in application probabilities under the strong competition incentive (i.e. the $\mathrm{T} 4 \times$ male interactions).

Figure 5 suggests a positive relationship between the $\mathrm{T} 4 \times$ male interactions and the cities' hourly market wage. For example, the three cities with the highest wage levels in our sample (San Francisco, Boston, and Washington DC) are also the cities with highly positive estimates of the $\mathrm{T} 4 \times$ male interactions. Note that in these cities median wages are at least $\$ 13$, and they are the closest to the mean wage that we offer of $\$ 15$. The figure also shows that the relationship between the $\mathrm{T} 4 \times$ male interactions and the cities' hourly market wage is less clear in cities where the wage levels are low. Only six out of thirteen cities have a positive T4 $\times$ male coefficient. Overall there is a positive correlation between market wages and $\mathrm{T} 4 \times$ male interactions $(\mathrm{r}=0.554, \mathrm{p}=0.026$, Pearson).

To more rigorously test whether application patterns are subject to market wages, we divide the sample into one group consisting of the three cities where wages are most comparable to the wage we offer, and another group where wages are considerably lower. Appendix Table D reports results from the regression using only the first group. We find that among these cities the gender gap in T4 is strong and statistically significant (model 1). Turning to the job task, when we restrict our focus to the sample of subjects expressing interest in the male advertisement (model 2 of Table D), we observe that the $\mathrm{T} 4 \times$ male interaction is the only significant interaction $(\mathrm{p}=0.023)$; all other treatment $\times$ gender interactions are insignificant at conventional levels $(\mathrm{p}>0.228)$. Appendix Table $\mathrm{E}$ reports results from the second group cities. We now observe that the overall $\mathrm{T} 4 \times$ male interaction is no longer significant $(\mathrm{p}=0.438$, model 1$)$. 
However, it is still significant at $\mathrm{p}=0.066$ for the male job advertisement sample (model 2). None of the other treatments interact significantly with gender in the thirteen cities where market wages are lower (i.e., below \$13).

As a robustness test on the extent to which each treatment's effect on the gender gap in applications depends on local wages, we estimate the predictive power of the wage on the change in the gap in each treatment controlling for other potential covariates. Table 6 reports results from an OLS model where we use the cities' hourly market wage to predict the treatment $\times$ male average marginal effects in each location, controlling for the cities' unemployment rate, supply of comparable jobs, and application questionnaire length. In Model 3, we see that market wage positively predicts the effects of the $\mathrm{T} 4 \times$ male interactions in each city at the $\mathrm{p}<.05$ level. Table 6 also shows the predictive power of local wages on the marginal effects on the gender gap of treatments other than T4. Market wages are insignificant predictors for T1\&T2 $\times$ male, T3 $\times$ male, and T5 $\times$ male, and do predict the $\mathrm{T} 6 \times$ male interaction $(\mathrm{p}=0.005)$.

We also observe in Table 6 that the application questionnaire length does not significantly affect any of the treatment $\times$ male interactions $(p>0.453)$. Recall that the application questionnaire length was randomized at the city level. Models 4 and 5 in Table 5 seem to suggest that the application questionnaire could itself play an important role for the $\mathrm{T} 4 \times$ male interaction, which is significant if the questionnaire is short (model 4) but insignificant if the questionnaire is long (model 5). However, model 3 in Table 6 suggests that the apparent relevance of the application questionnaire for the gender gap is in fact substantially driven by other city level variables that co-vary with the questionnaire length. In particular, market wages seem to explain the apparent importance of the application questionnaire for the gender gap observed in Table 5. If we were to use only application questionnaire length in model 3 of Table 
6 , then it would be significant ( $\mathrm{p}=0.069$, not shown), but upon controlling for market wages, the application questionnaire length becomes insignificant.

\subsection{The gender gap and individual characteristics}

Individuals who responded to our job advertisements are of varying ages (mean $=27.9$ years, approximately two-thirds are 22-30 years, $\min .=18, \max .=68),{ }^{18}$ and have a range of different educational backgrounds and work experience. For example, $44.9 \%$ of the applicants have a bachelor's degree and $57.4 \%$ have had at least some college. The majority of applicants has experience as an administrative assistant (variable: job experience, 70.5 percent).

In Table B in the appendix, we control for education and job experience in our main regression models. We find that both variables are significant predictors for the decision to apply (job experience is associated with lower likelihood of applying, more education with higher likelihood), but that our main findings are not affected by including them in the regressions despite the fact that our female subjects are more likely to have job experience and are less educated than our male subjects $(\mathrm{p}<0.001)$.

Comparing these two attributes across those job-seekers which select into each compensation method (i.e. those who choose to apply under each treatment), we find no statistically significant differences. Neither mean job experience (Kruskal-Wallis equality of populations rank test, $\mathrm{p}=0.535)$ nor mean education $(\mathrm{p}=0.117)$ are statistically different across the six groups of applicants in T1-T6. Moreover, if we regress job experience or education on treatments, gender,

\footnotetext{
${ }^{18}$ We did not ask participants for their age but instead derived the age from information on the individuals' CVs such as their graduation year. We could infer the age only from 4620 of our 6779 subjects. While controlling for age decreases the sample size, we do not find that it affects application patterns. In general, we observe that older subjects are less likely to apply.
} 
and the treatment $\times$ gender interactions, none of the coefficients on the interactions are significant.

Job experience and education are arguably imprecise indicators of the qualifications of jobseekers for our particular jobs. Thus, they may not satisfactorily reveal whether the sample of applicants differs in relevant abilities between our treatments. To amend for this shortcoming, we make use of the questionnaire responses in the applications and investigate their informational content. Recall that when subjects replied to the questionnaires, subjects already knew the salary scheme, and that by sending us their response they were choosing to apply. We therefore have questionnaire responses only for those subjects who chose to become applicants.

We had four independent auditors (two women and two men), blind to the project, treatments, and the gender of the applicants (we removed all identifiers of gender from the responses) rank applicants according to the "applicants' ability to perform the advertised job tasks". ${ }^{19}$ Each auditor evaluated in total 400 application questionnaires which were randomly drawn from the full sample and differed in applicant's gender and compensation scheme (whether application was for the fixed wage treatments $\mathrm{T} 1 / \mathrm{T} 2$ or the individual competition treatments T3 and T4). Moreover, auditors rated how confident the applicants perceive themselves to perform the job. ${ }^{20}$ From this exercise comes our last result:

\footnotetext{
${ }^{19}$ The ranked ability to perform the job tasks correlates significantly with the applicants' job experience ( $\mathrm{r}=0.083$, $\mathrm{p}=0.001)$ and education $(\mathrm{r}=0.153, \mathrm{p}<0.001)$. Job applicants are better ranked, if they have job experience and a higher level of education.

${ }^{20}$ Gender differences in (over-) confidence may be a potential source of gender differences in competitiveness (Barber and Odean, 2001). While perhaps less direct than other approaches to evaluating self-confidence, the virtue of this method lies in keeping the job application process as natural and as similar to typical applications as possible, which was of critical importance to us. In addition, we had two more questions related more indirectly to ability ("Would you hire the applicant?" and "How well does the applicant answer the question?"). We do not report the analysis of these two questions because they lead to qualitatively very similar findings to those for the direct question about the applicants' ability.
} 
Result 6. Men of low abilities are over-proportionally attracted by wage compensation schemes that depend heavily on individual relative performance.

Figure 6 illustrates gender-specific sorting according to abilities into the different compensation environments controlling for rater fixed effects and confidence. We see that the mean ability of women slightly increases as competition is introduced. In T1 and T2, $42.7 \%$ of the female applicants are classified as 'able' or 'very able', in treatment T3 this percentage is $50.9 \%$, and in treatment $\mathrm{T} 4$ it is $54.7 \%$. This pattern is very different for men. For men, ability increases from treatments $\mathrm{T} 1$ and $\mathrm{T} 2$ to $\mathrm{T} 3$, but sharply decreases when competition is intensified. For example, in treatment T4, only $37.3 \%$ of the male applicants are classified as 'able' or 'very able' whereas the corresponding percentage is $48.8 \%$ in treatments $\mathrm{T} 1$ and $\mathrm{T} 2$ and $54.7 \%$ in treatment $\mathrm{T} 3$.

Model 1 in Appendix B Table F shows the formal statistical results underlying Figure 6. The dependent variable is the applicants' rated ability to perform the advertised job. For simplicity, we categorized the responses into two categories: (i) 'not able' (consisting of the responses 'not able', chosen in $11.6 \%$ of the cases, and the response 'somewhat able' which was chosen in $40.7 \%$ of the cases) and (ii) 'able' (categories 'able': $39 \%$ and 'very able': $8.7 \%$ ). ${ }^{21}$ We find that the drop in men's abilities from treatments $\mathrm{T} 1$ and $\mathrm{T} 2$ to $\mathrm{T} 4$ is significant at the $\mathrm{p}=0.024$ level (model 1, T4 dummy). Moreover, we observe that the T4 $\times$ female interaction is highly significant and positive, confirming the gender gap in rated abilities in the compensation environment where wages depend heavily on individual relative performance.

${ }^{21}$ The findings are not subject to this categorization. 
Finally, model 2 in Table F indicates that there is no gender-specific sorting into treatment T4. The dependent variable in this model is the rater's perceived level of confidence from the job-applicants. We neither observe that these confidence levels significantly change for men when moving from treatments $\mathrm{T} 1$ and $\mathrm{T} 2$ to $\mathrm{T} 4(\mathrm{p}=0.511)$, nor that there is an interaction between treatment $\mathrm{T} 4$ and gender $(\mathrm{p}=0.429)$. This means it is unlikely that gender differences in confidence are what is driving the gender gap induced by the compensation scheme where wages depend heavily on individual relative performance. This result provides an important insight into why we might be observing the gender differences we observe in labor markets. More research is necessary on this point, however, as confidence might be measured with error.

\section{Discussion}

A pillar of economics is that incentives matter. The sociology and management literatures have long studied the role of both financial and non-financial incentives within firms and organizations. The seminal contract theory work of Hart and Holmstrom (1987) and the proliferation of personnel economics (Lazear 1995) has helped to usher such incentive questions into the mainstream of labor economics.

Our research takes this broader literature into a different direction to explore how the compensation scheme influences worker sorting. An earlier generation of empirical studies exploited firm's personnel data to measure the productivity effects of compensation schemes on individual workers (see List and Rasul 2010, for a review). An econometric challenge facing these studies is that observed incentive contracts are endogenously determined (Prendergast 1999, Chiappori and Salanie 2003). This means that identifying causal effects of incentives on behavior is confounded by the presence of unobservables, such as managerial practices or 
workplace amenities, that determine both which compensation schemes are chosen, and worker productivity. In earlier research relying on cross-sectional variation this concern has been addressed using instrumental variables (Groves et al., 1994). However, this concern applies even if such effects are identified purely from within firm observations (Jones and Kato, 1995; Ichniowski et al., 1997; Paarsch and Shearer, 1999 \& 2000; Lazear, 2000).

Field experiments introduce exogenously timed variation in incentive structures that are orthogonal to other management practices or workplace amenities. This provides us with the opportunity to identify the causal impact of compensation regimes on the behavior of individual job seekers. In this way, our study extends a rich literature on gender-based behavioral differences in several meaningful ways. First, by taking the experiment to the field we are provided with a glimpse of whether, and to what extent, gender preferences influence the first stage of the hiring decision. As our subjects do not know that they are being experimentally observed, we remove the risk that their choices are influenced by experimenter expectations, heightened sensitivity to gender norms, or other similar threats to causal interpretation. Second, by randomly varying the compensation scheme faced by an individual who has already expressed interest in a job, we isolate the impact of the salary regime on the gender balance of applicants, which is likely to influence gender composition of employees. In doing so, we find that women are generally more sensitive to divergences from fixed-wage compensation. In particular, we find that competitive workplaces can in fact significantly decrease the propensity of women to apply for a job compared to that of men.

Complementary treatments provide important boundary conditions for this result, however. For instance, while the dissuasive effect of competition-based compensation on women can be strong and significant when stakes of the competition are on the order of $50 \%$ of base-wage, the 
effect substantially diminishes when the stakes of relative performance drop to $22 \%$ of the basewage. In addition, including a team element to the competitive environment, such that compensation depends on the relative performance of a group of workers to which one belongs can considerably attenuate the gender gap.

Whether competition disproportionately discourages women from applying to a job also appears to heavily depend on the job-task and possibly the gender norms surrounding the task. Among job-seekers interested in the "female" ad, which redefines the job-task so as to remove associations with activities that may be construed as "male," neither of the competition treatments changes the gender balance among applicants. This result suggests that previous findings regarding gender differences in preferences for competition are based at least in part on the nature of the task performed. In field settings, when economic agents are faced with choices regarding job-selection, the nature of the work matters. Therefore, descriptive framing of the jobs and their potential gender associations may play a key role in the ultimate sorting of workers.

We also find that broader market conditions play a crucial role in gender-dependent responses to highly competitive workplaces. The gender gap induced by high competition incentives is critically linked to the local labor market. For instance, we find that women are most likely to be deterred from competitive work environments when viable outside options are available. This suggests that women are responding appropriately to 'prices,' in the sense that they are trading off lower fixed wages with more competitive job environments.

Complementary analysis offers some suggestive evidence as to the causal mechanism driving the gender gap observed. Readily observable characteristics such as education and jobexperience appear to have no effect on how an individual responds to different contract environments; however, a blind analysis of the quality of interview questionnaire responses 
suggests that the highly competitive regime disproportionately attracts low-ability males. This is consistent with the hypothesis that "males compete too much" - i.e., more than what would maximize monetary payoffs (Niederle and Vesterlund, 2007).

In closing, some words of caution are in order. First, it is important to recognize that we have chosen a specific type of job in our natural field experiment. We chose an office support position both because it is the most common occupation in the country and also because it is a relatively easy job to create. In 2008 and 2009, office and administrative support jobs were the most common type of position to hold, accounting for over $13 \%$ of the workforce (Bureau of Labor Statistics). It is possible, however, that office support positions attract fewer competitive types, compared for example to a sales position. Whether the job type interacts with the gender gap is an important issue that remains unresolved. Second, we explore job applications and not final acceptance of the job. In this manner, we are observing a critical first step in the hiring process to learn more about gender preferences. In as much as learning about the ultimate distribution of workers, we can say less because of this goal. ${ }^{22}$ This represents a fruitful avenue for future research.

\footnotetext{
${ }^{22}$ However, recall that the gender distribution of our subjects interested by the job-ad that removed male-oriented language closely mirrors the actual gender distribution in the US workforce for this type of job, underscoring the importance of application patterns for realized labor force composition.
} 


\section{Author affiliations:}

Jeffrey A. Flory: University of Maryland, Department of Agricultural and Resource Economics, 2200 Symons Hall, College Park, MD 20742, jflory@arec.umd.edu.

Andreas Leibbrandt (corresponding author): University of Chicago, Department of Economics,1126 E 59 ${ }^{\text {th }}$ Street, Chicago, IL 60637. Email: leibbrandt@uchicago.edu and Workshop in Political Theory and Policy Analysis, Indiana University.

John A. List: University of Chicago, Department of Economics, 1126 E $59^{\text {th }}$ Street, Chicago, IL 60637 and NBER, Email: jlist@uchicago.edu. 


\section{TABLES 1-6}

Table 1: Characterization of compensation scheme treatments (T1-T6)

\begin{tabular}{|l|c|c|c|c|c|}
\hline & $\begin{array}{c}\text { minimal } \\
\text { hourly wage }\end{array}$ & $\begin{array}{c}\text { maximal } \\
\text { hourly wage }\end{array}$ & $\begin{array}{c}\text { individual } \\
\text { relative } \\
\text { performance? }\end{array}$ & $\begin{array}{c}\text { wage dependent on ... } \\
\text { team relative } \\
\text { performance? }\end{array}$ & risk/uncertainty \\
\hline T1 \& T2 & 15 & 15 & & & \\
\hline T3 & 13.5 & 16.5 & $X$ & & \\
\hline T4 & 12 & 18 & $X$ & & \\
\hline T5 & 12 & 18 & & $X$ & \\
\hline T6 & 13.5 & 16.5 & & & \\
\hline
\end{tabular}

Table 2: Summary statistics

\begin{tabular}{|c|c|c|c|c|c|}
\hline & \multirow{2}{*}{ total } & female-oriented & male-oriented & \multirow{2}{*}{$\begin{array}{c}\text { short } \\
\text { questionnaire }\end{array}$} & \multirow{2}{*}{$\begin{array}{c}\text { long } \\
\text { questionnaire }\end{array}$} \\
\hline & & ad & ad & & \\
\hline Job-seekers total $(\mathrm{N})$ & 6779 & 4239 & 2540 & 3598 & 3181 \\
\hline in T1 & 1143 & 709 & 434 & 604 & 539 \\
\hline in $\mathrm{T} 2$ & 1130 & 701 & 429 & 600 & 530 \\
\hline in T3 & 1127 & 705 & 422 & 592 & 535 \\
\hline in $\mathrm{T} 4$ & 1133 & 703 & 430 & 603 & 530 \\
\hline in $\mathrm{T} 5$ & 1112 & 701 & 411 & 588 & 524 \\
\hline in T6 & 1134 & 720 & 414 & 611 & 523 \\
\hline Job-applications T1-T6 (probability) & 0.398 & 0.369 & 0.447 & 0.406 & 0.39 \\
\hline Women's job-applications T1-T6 & 0.362 & 0.358 & 0.372 & 0.363 & 0.362 \\
\hline Men's job-applications T1-T6 & 0.484 & 0.414 & 0.534 & 0.493 & 0.472 \\
\hline Words in questionnaire (mean) & 217.9 & 214.2 & 222.8 & 116.7 & 337.8 \\
\hline
\end{tabular}




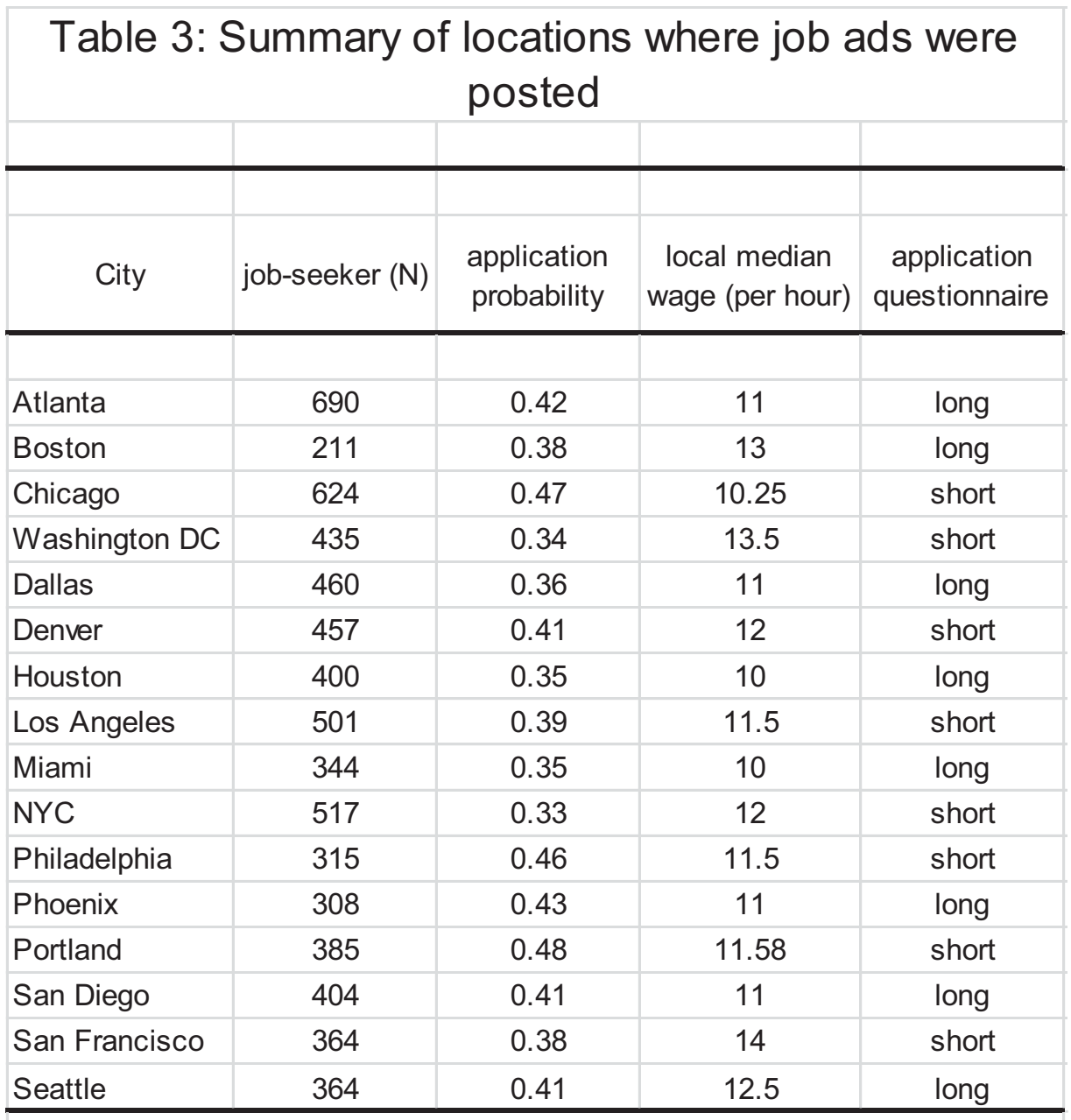

Notes: In each given city the median wage was collected from posted wages of similar jobs. Application questionnaire length was randomly assigned. 


\begin{tabular}{|c|c|c|c|c|c|}
\hline \multicolumn{6}{|c|}{$\begin{array}{c}\text { Table 4: Application probabilities depending on gender and } \\
\text { treatments }\end{array}$} \\
\hline & \multirow[b]{2}{*}{ treatment } & \multicolumn{2}{|c|}{ female-oriented job ad } & \multicolumn{2}{|c|}{ male-oriented job ad } \\
\hline & & female & male & female & male \\
\hline \multirow{6}{*}{$\begin{array}{c}\text { short } \\
\text { questionnaire }\end{array}$} & $\mathrm{T} 1$ & 0.42 & 0.45 & 0.47 & 0.61 \\
\hline & $\mathrm{T} 2$ & 0.46 & 0.46 & 0.39 & 0.58 \\
\hline & T3 & 0.31 & 0.38 & 0.38 & 0.54 \\
\hline & T4 & 0.30 & 0.34 & 0.28 & 0.64 \\
\hline & T5 & 0.27 & 0.34 & 0.32 & 0.44 \\
\hline & T6 & 0.40 & 0.47 & 0.40 & 0.53 \\
\hline \multirow{6}{*}{$\begin{array}{c}\text { long } \\
\text { questionnaire }\end{array}$} & $\mathrm{T} 1$ & 0.42 & 0.50 & 0.42 & 0.51 \\
\hline & T2 & 0.40 & 0.60 & 0.48 & 0.58 \\
\hline & T3 & 0.34 & 0.40 & 0.37 & 0.50 \\
\hline & T4 & 0.34 & 0.34 & 0.32 & 0.51 \\
\hline & T5 & 0.32 & 0.36 & 0.35 & 0.45 \\
\hline & T6 & 0.33 & 0.36 & 0.28 & 0.47 \\
\hline
\end{tabular}

Notes: Numbers show the application probabilities for women and men. 


\section{Table 5: Probability of job application (logit)}

\begin{tabular}{|c|c|c|c|c|c|}
\hline Model & (1) & (2) & (3) & (4) & (5) \\
\hline Sample & full & male job ad & female job ad & $\begin{array}{c}\text { short } \\
\text { questionnaire }\end{array}$ & $\begin{array}{c}\text { long } \\
\text { questionnaire }\end{array}$ \\
\hline \multirow{2}{*}{ T3 } & $-0.087^{\star * *}$ & $-0.068^{*}$ & $-0.093^{* * *}$ & $-0.103^{* * *}$ & $-0.070^{* *}$ \\
\hline & $(0.000)$ & $(0.080)$ & $(0.000)$ & $(0.000)$ & $(0.017)$ \\
\hline \multirow{2}{*}{ T4 } & $-0.117^{\star \star *}$ & $-0.147^{* * *}$ & $-0.104^{* * *}$ & $-0.144^{* * *}$ & $-0.090^{* * *}$ \\
\hline & $(0.000)$ & $(0.000)$ & $(0.000)$ & $(0.000)$ & $(0.003)$ \\
\hline \multirow{2}{*}{ T5 } & $-0.127^{* * *}$ & $-0.110^{* * *}$ & $-0.132^{* * *}$ & $-0.158^{* * *}$ & $-0.095^{* * *}$ \\
\hline & $(0.000)$ & $(0.005)$ & $(0.000)$ & $(0.000)$ & $(0.001)$ \\
\hline \multirow{2}{*}{ T6 } & $-0.068^{* * *}$ & $-0.105^{* *}$ & $-0.052^{* *}$ & -0.036 & $-0.102^{* * *}$ \\
\hline & $(0.001)$ & $(0.010)$ & $(0.030)$ & $(0.218)$ & $(0.001)$ \\
\hline \multirow{2}{*}{ male } & $0.106^{* * *}$ & $0.124^{* * *}$ & $0.065^{* *}$ & $0.096^{* * *}$ & $0.118^{* * *}$ \\
\hline & $(0.000)$ & $(0.000)$ & $(0.030)$ & $(0.001)$ & $(0.000)$ \\
\hline \multirow{2}{*}{ T3 $\times$ male } & 0.022 & 0.020 & -0.000 & 0.050 & -0.011 \\
\hline & $(0.555)$ & $(0.723)$ & $(0.999)$ & $(0.316)$ & $(0.845)$ \\
\hline \multirow{2}{*}{$\mathrm{T} 4 \times$ male } & $0.070^{*}$ & $0.153^{* * *}$ & -0.035 & $0.129^{* *}$ & -0.003 \\
\hline & $(0.064)$ & $(0.009)$ & $(0.525)$ & $(0.011)$ & $(0.957)$ \\
\hline \multirow{2}{*}{ T5 $\times$ male } & 0.003 & -0.012 & 0.007 & 0.035 & -0.030 \\
\hline & $(0.937)$ & $(0.836)$ & $(0.906)$ & $(0.505)$ & $(0.607)$ \\
\hline \multirow{2}{*}{ T6 $\times$ male } & 0.012 & 0.044 & -0.006 & 0.016 & -0.012 \\
\hline & $(0.749)$ & $(0.445)$ & $(0.905)$ & $(0.751)$ & $(0.837)$ \\
\hline City fixed effects? & yes & yes & yes & yes & yes \\
\hline $\mathrm{N}$ & 6779 & 2540 & 4239 & 3598 & 3181 \\
\hline \multicolumn{6}{|c|}{$\begin{array}{l}\text { Notes: }{ }^{* * *} p<0.01,{ }^{* *} p<0.05,{ }^{*} p<0.1 \text {. Coefficients present average marginal effect, i.e. differences in application } \\
\text { probabilities. Omitted category= women in T1\&T2. P-values in parenthesis. Robust standard errors used. Male = } 0 \text { if } \\
\text { subject is female. } T 1 \& T 2=\text { treatments with fixed hourly wages }=\$ 15 . T 3=\text { treatment in which compensation } \\
\text { depends mildly on individual relative performance. If subject underperforms hourly wage }=\$ 13.5 \text {, if she outperforms a } \\
\text { competitor hourly wage }=\$ 16.5 . T 4=\text { treatment in which compensation depends strongly on individual relative } \\
\text { performance. If subject underperforms hourly wage }=\$ 12 \text {, if she outperforms a competitor hourly wage }=\$ 18 . \mathrm{T} 5= \\
\text { treatment in which compensation depends on relative team performance. If team underperforms hourly wage }=\$ 12 \text {, } \\
\text { if team outperforms a competing team hourly wage }=\$ 18 . T 6=\text { treatment in which compensation depends on } \\
\text { uncertainty, hourly wage is either } \$ 13.5 \text { or } \$ 16.5 .\end{array}$} \\
\hline
\end{tabular}




\section{Table 6: Predicting application patterns on city level with city market wages (OLS)}

\begin{tabular}{|c|c|c|c|c|c|}
\hline Model & (1) & (2) & (3) & (4) & (5) \\
\hline Dependent variable & male in T1\&T2 & T3 $\times$ male & $\mathrm{T} 4 \times$ male & T5 $\times$ male & T6 $\times$ male \\
\hline \multirow[b]{2}{*}{ market wage } & -0.024 & 0.060 & $0.112^{* *}$ & 0.058 & $0.148^{* * *}$ \\
\hline & $(0.324)$ & $(0.123)$ & $(0.049)$ & $(0.224)$ & $(0.005)$ \\
\hline \multirow{2}{*}{$\begin{array}{c}\text { short application } \\
\text { questionnaire? }\end{array}$} & -0.049 & 0.061 & 0.067 & 0.026 & -0.066 \\
\hline & $(0.453)$ & $(0.628)$ & $(0.601)$ & $(0.749)$ & $(0.522)$ \\
\hline \multirow{2}{*}{ unemployment rate } & 0.019 & 0.030 & $0.036^{*}$ & -0.045 & 0.011 \\
\hline & $(0.112)$ & $(0.249)$ & $(0.096)$ & $(0.104)$ & $(0.614)$ \\
\hline \multirow{2}{*}{ job supply } & $-0.003^{*}$ & $0.006^{* *}$ & 0.004 & -0.003 & 0.002 \\
\hline & $(0.080)$ & $(0.015)$ & $(0.239)$ & $(0.164)$ & $(0.582)$ \\
\hline \multirow{2}{*}{ constant } & 0.301 & $-1.180^{* *}$ & $-1.774^{* * *}$ & -0.205 & $-1.732^{\star \star *}$ \\
\hline & $(0.262)$ & $(0.050)$ & $(0.008)$ & $(0.790)$ & $(0.006)$ \\
\hline R-squared & 0.379 & 0.216 & 0.481 & 0.463 & 0.525 \\
\hline
\end{tabular}

Notes: ${ }^{* * *} \mathrm{p}<0.01,{ }^{* *} \mathrm{p}<0.05,{ }^{*} \mathrm{p}<0.1 . \mathrm{N}=16$; i.e. one observation per city. Numbers in parentheses are $\mathrm{p}$-values. Regression estimated with robust standard errors. All variables are on city level. Market wage is estimated for jobs comparable to our advertised job on same online job board. Unemployment rate $=$ the unemployment rate in the corresponding city one month before the job was advertised. Job supply = Number of subjects who signalled interest in our job advertisements divided by number of advertised comparable jobs on same online job board. Short application questionnaire $=1$ if questionnaire is short, 0 if questionnaire is long. 


\section{FIGURES 1-6}

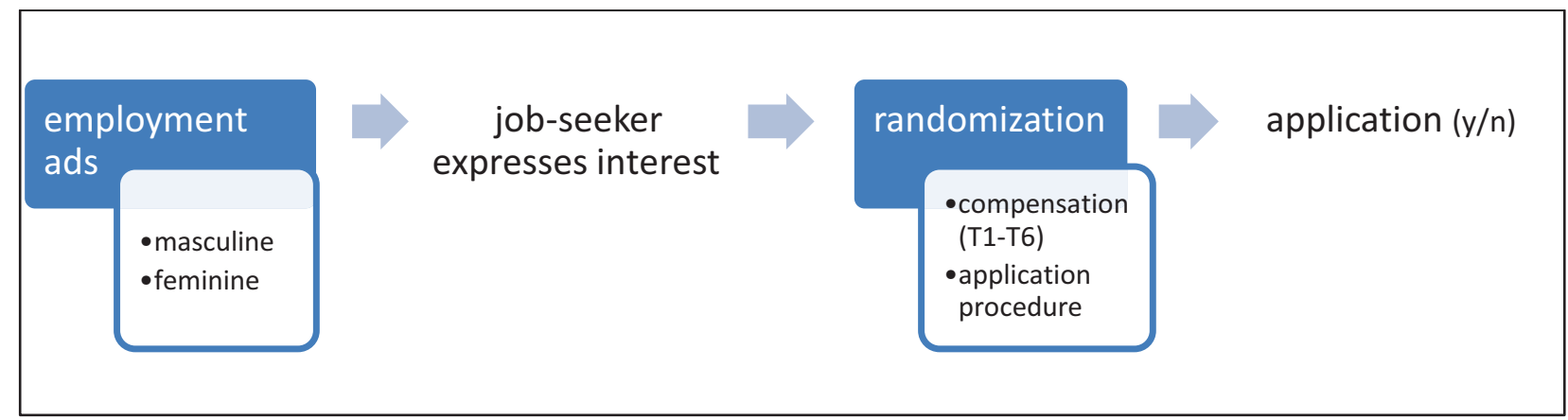

Figure 1: Experimental Design (two-step method).

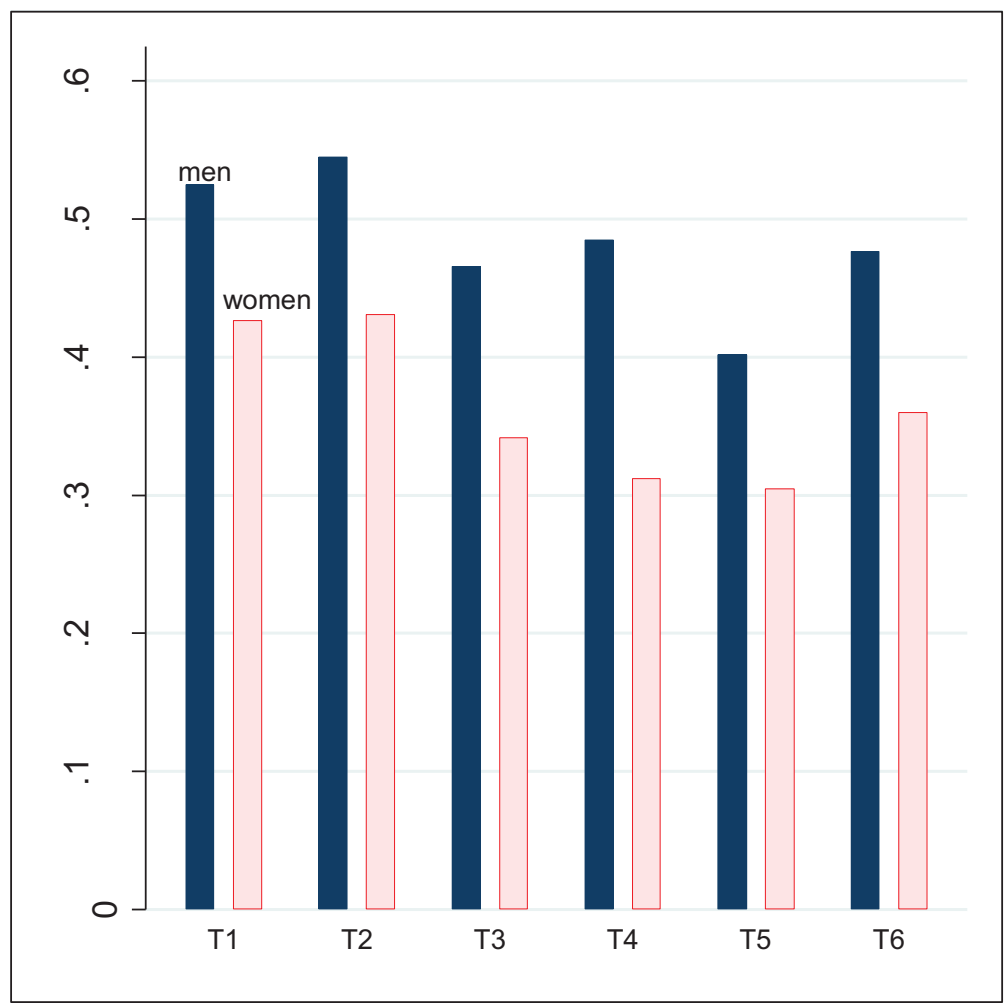

Figure 2: Application patterns depending on treatment and gender.

Notes: T1\&T2= fixed wages either team (T1) or no team work(T2), T3= base wage $+22 \%$ bonus depending on individual relative performance, T4= base wage $+50 \%$ bonus depending on individual relative performance, $\mathrm{T} 5=$ base wage $+50 \%$ bonus depending on team relative performance, $T 6=$ base wage $+22 \%$ bonus depending on uncertainty. 


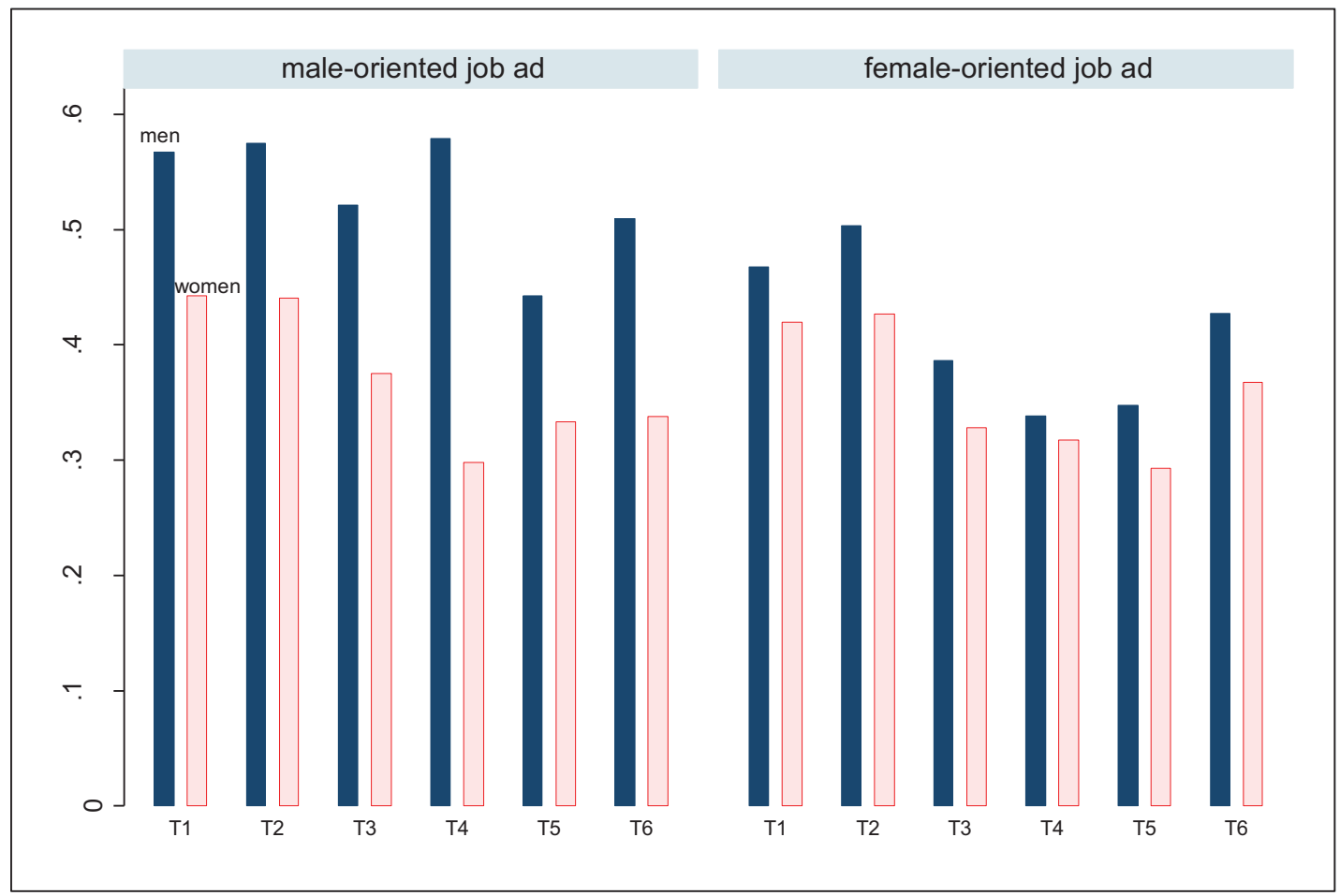

Figure 3 (left): Application pattern for the male-oriented job ad.

Figure 4 (right): Application pattern for the female-oriented job ad.

Notes: T1\&T2= fixed wages either team(T1) or no team work(T2), T3= base wage $+22 \%$ bonus depending on individual relative performance, $\mathrm{T} 4=$ base wage $+50 \%$ bonus depending on individual relative performance, T5 $=$ base wage $+50 \%$ bonus depending on team relative performance, $\mathrm{T} 6=$ base wage $+22 \%$ bonus depending on uncertainty. 


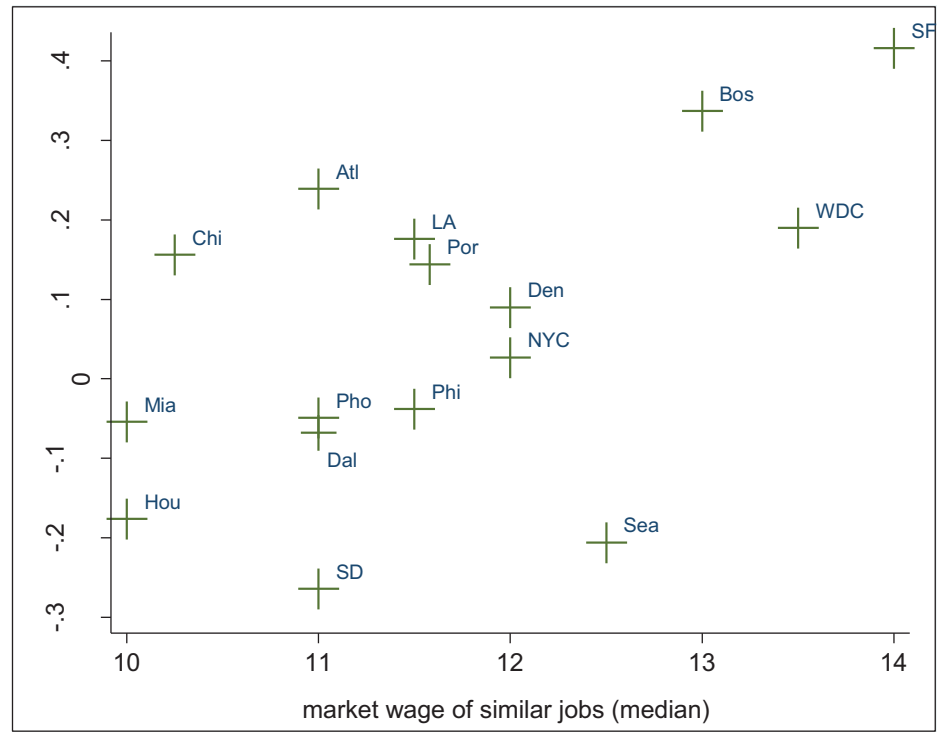

Figure 5: Market wages and gender differences in willingness to apply to competitive workplaces.

Notes: The $y$-axis shows marginal effects of the T4 $\times$ male interaction for each corresponding city; i.e., the gender difference-in-differences between a fixed-wage job and the same job with compensation depending heavily on individual performance. Positive numbers indicate a gender gap because women disproportionally avoid applying to competitive workplaces. City names are abbreviated.

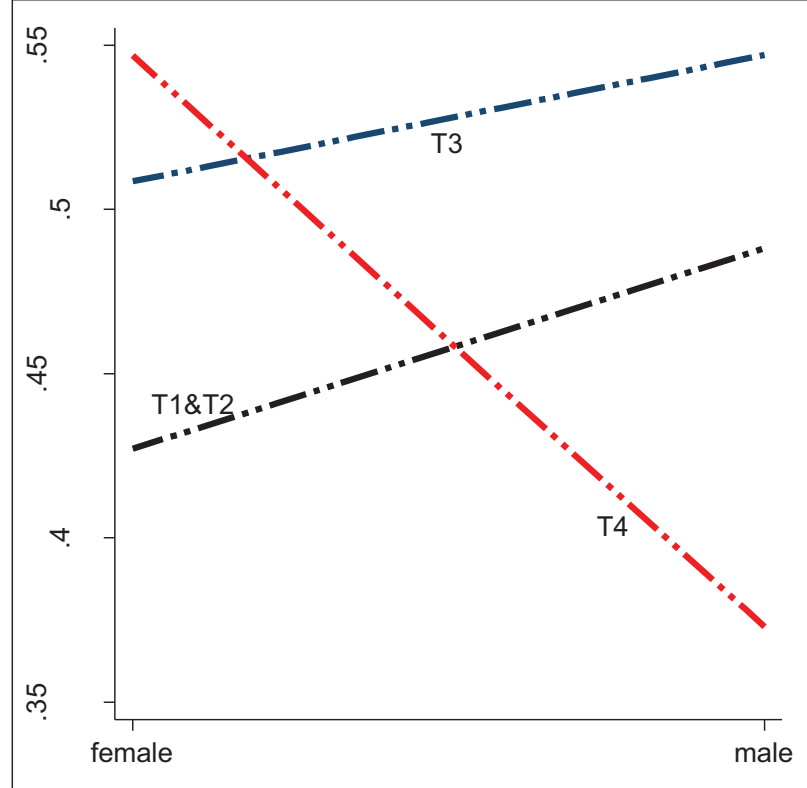

Figure 6: Probability job-applicant is rated as able.

Notes: Lines connect mean female to mean male rated ability. T1\&T2=fixed wages either team or no team work, T3= base wage $+22 \%$ bonus depending on individual relative performance, $\mathrm{T} 4=$ base wage $+50 \%$ bonus depending on individual relative performance 


\section{Appendix A: Scripts}

\section{A1. Male job advertisement}

Posting Category: admin/office jobs

Title: Seeking Sports News Assistant

The \{insert affiliation is seeking a \{insert city\} -area administrative assistant to help gather information on sports stories in the \{insert city\} region. While the \{insert affiliation\} is based in Chicago, we have a satellite project in \{insert city\}. The assistant will provide us with up-to-date information on local news and views on basketball, football, baseball, soccer, Nascar, golf, tennis, hockey, and other sports.

Responsibilities for the position include reading local sports-related news coverage (pro-, semi-pro, and college), and preparing short reports. The successful candidate will also be comfortable with typical administrative duties - light correspondence, proofreading, filing, email and phone communication, etc.

If you are interested, please email us your CV or resume, attention: Name A (gender not recognizable)

Name (gender not recognizable)

Affiliation

Address

Compensation: Hourly

Location: \{insert city\} 


\section{A2. Female job advertisement}

Posting Category: admin/office jobs

Title: Administrative Assistant

The \{insert affiliation\} is hiring a \{insert city\} -area administrative assistant to help gather information on a variety of local news issues in the \{insert city\} region. While the \{insert affiliation $\}$ is based in Chicago, we have a satellite project in \{insert city\}. The assistant will provide us with up-to-date information on community events, arts and culture, business, entertainment, policy issues, crime, and other stories.

Responsibilities for the position include seeking out, reading, and summarizing local news stories and preparing short reports. The successful candidate will also be comfortable with typical administrative duties - light correspondence, proofreading, filing, email and phone communication, etc.

If you are interested, please email us your CV or resume, attention: Name B (gender not recognizable)

Name (gender not recognizable)

Affiliation

Address

Compensation: Hourly

Location: \{insert city\} 


\section{B. Response to job-seekers who replied to job advertisements (for T1-T6)}

Thank you for your interest in the position.

We are sending this general first response to interested applicants. We apologize if you have any unanswered questions. If you still have questions about the position, please send them, along with your responses to the enclosed interview questions, to complete your application.

\{for T1\} First, a little more information about the job: As the work is best done in teams, you will be paired with one co-worker. We have frequent deadlines, and timely quality information from you is important. The position pays $\$ 15 / \mathrm{hr}$.

\{for T2\} First, a little more information about the job: We have frequent deadlines, and timely quality information from you is important. The position pays $\$ 15 / \mathrm{hr}$.

\{for T3\} First, a little more information about the job: We have frequent deadlines, and timely quality information from you is important. You will be paired with one other person we are also currently hiring into the same position. The base wage for the position is $\$ 13.50 / \mathrm{hr}$ plus a bonus, which translates to an additional $\$ 3 / \mathrm{hr}$, if you perform better than this co-worker. Thus, the wage is either $\$ 13.50 / \mathrm{hr}$ or $\$ 16.50 / \mathrm{hr}$, depending on which of you does best.

\{for T4\} First, a little more information about the job: We have frequent deadlines, and timely quality information from you is important. You will be paired with one other person we are also currently hiring into the same position. The base wage for the position is $\$ 12 / \mathrm{hr}$ plus a bonus, which translates to an additional $\$ 6 / \mathrm{hr}$, if you perform better than this co-worker. Thus, the wage is either $\$ 12 / \mathrm{hr}$ or $\$ 18 / \mathrm{hr}$, depending on which of you does best. ${ }^{23}$

\{for T5\} First, a little more information about the job: As the work is best done in teams, you will be paired with one co-worker. We have frequent deadlines, and timely quality information from you is important. The wage for the position is $\$ 12 / \mathrm{hr}$ plus a bonus, which translates to an additional $\$ 6 / \mathrm{hr}$, if your team performs better than another team. Thus, the wage is either $\$ 12 / \mathrm{hr}$ or $\$ 18 / \mathrm{hr}$, depending on which pair does best.

\{for T6\} First, a little more information about the job: We have frequent deadlines, and timely quality information from you is important as it is the basis for journal publication. The base wage for the position is $\$ 13.50 / \mathrm{hr}$, plus an hourly bonus of $\$ 3 / \mathrm{hr}$ if your assistance contributes to the publication of articles.

\footnotetext{
${ }^{23}$ We also used scripts for T3 and T4 that started the second sentence with: "As the work is best done in teams, $(\ldots)^{\prime \prime}$
} 
If you are interested, please answer the attached interview questions with a few sentences each, and return them to us. Please also include your CV or resume (if not already sent to us), and any remaining questions you have about the position, along with your answers to the interview questions.

Best regards,

Name (gender not recognizable)

Affiliation

Address

\section{C1. Short interview questionnaire}

Please write a few sentences describing why you are interested in this position.

\section{C2. Long interview questionnaire}

Please answer the following questions with a few sentences each.

How would you describe yourself?

Please write a few sentences describing why you are interested in this position.

How would you describe your ideal work environment?

Please tell us about a major problem you have recently encountered, or a challenge you have

encountered in a past position, and how you solved the problem or addressed the challenge. 


\section{Appendix B: Tables A-F and Figure A}

Table A: Probability of job application, omitted category is women in
T1 (logit)

\begin{tabular}{|c|c|c|c|}
\hline Model & (1) & (2) & (3) \\
\hline Sample & full & male job ad & female job ad \\
\hline \multirow{2}{*}{ T2 } & 0.007 & -0.002 & 0.008 \\
\hline & $(0.778)$ & $(0.958)$ & $(0.783)$ \\
\hline \multirow{2}{*}{ T3 } & $-0.083^{\star \star \star}$ & -0.070 & $-0.089^{\star \star \star}$ \\
\hline & $(0.001)$ & $(0.125)$ & (0.002) \\
\hline \multirow{2}{*}{ T4 } & $-0.114^{* * *}$ & $-0.148^{* * *}$ & $-0.100^{* * *}$ \\
\hline & $(0.000)$ & $(0.002)$ & $(0.000)$ \\
\hline \multirow{2}{*}{ T5 } & $-0.123^{* * *}$ & $-0.112^{* *}$ & $-0.128^{* * *}$ \\
\hline & (0.000) & (0.015) & (0.000) \\
\hline \multirow{2}{*}{ T6 } & $-0.065^{\star * *}$ & $-0.106^{* *}$ & $-0.048^{*}$ \\
\hline & (0.007) & (0.024) & (0.083) \\
\hline \multirow{2}{*}{ male } & $0.103^{* * *}$ & $0.120^{\star * *}$ & 0.056 \\
\hline & $(0.001)$ & $(0.010)$ & $(0.180)$ \\
\hline \multirow{2}{*}{$\mathrm{T} 2 \times$ male } & 0.005 & 0.009 & 0.019 \\
\hline & $(0.900)$ & $(0.893)$ & $(0.753)$ \\
\hline \multirow{2}{*}{$\mathrm{T} 3 \times$ male } & 0.025 & 0.025 & 0.009 \\
\hline & $(0.567)$ & $(0.709)$ & $(0.886)$ \\
\hline \multirow{2}{*}{ T4 $\times$ male } & $0.072^{*}$ & $0.157^{\star *}$ & -0.026 \\
\hline & $(0.094)$ & $(0.018)$ & $(0.674)$ \\
\hline \multirow{2}{*}{ T5 $\times$ male } & 0.005 & -0.008 & 0.015 \\
\hline & $(0.902)$ & $(0.908)$ & $(0.805)$ \\
\hline \multirow{2}{*}{ T6 $\times$ male } & 0.014 & 0.049 & 0.002 \\
\hline & $(0.738)$ & $(0.465)$ & $(0.968)$ \\
\hline City fixed effects? & yes & yes & yes \\
\hline
\end{tabular}

Notes: ${ }^{* *} p<0.01,{ }^{* *} p<0.05,{ }^{*} p<0.1$. Coefficients present average marginal effect, i.e. differences in application probabilities. Omitted category $=\mathrm{w}$ omen in T1. P-values in parenthesis. Robust standard errors used. Male $=0$ if subject is female. T1 \& T2 = treatments $w$ ith fixed hourly $w$ ages $=\$ 15 . T 3=$ treatment in $w$ hich compensation depends mildly on individual relative performance. If subject underperforms hourly wage $=\$ 13.5$, if she outperforms a competitor hourly $w$ age $=\$ 16.5$. T4 $=$ treatment in $w$ hich compensation depends strongly on individual relative performance. If subject underperforms hourly wage $=\$ 12$, if she outperforms a competitor hourly wage $=\$ 18$. T5 = treatment in which compensation depends on relative team performance. If team underperforms hourly wage $=\$ 12$, if team outperforms a competing team hourly $w$ age $=\$ 18$. T6 $=$ treatment in which compensation depends on uncertainty, hourly $w$ age is either $\$ 13.5$ or $\$ 16.5$. 


\section{Table B: Probability of job application using additional controls (logit)}

\begin{tabular}{|c|c|c|c|}
\hline Model & (1) & (2) & (3) \\
\hline Sample & full & male job ad & female job ad \\
\hline \multirow{2}{*}{ T3 } & $-0.083^{* * *}$ & $-0.071^{*}$ & $-0.086^{* * *}$ \\
\hline & $(0.000)$ & $(0.086)$ & $(0.001)$ \\
\hline \multirow{2}{*}{ T4 } & $-0.114^{\star \star *}$ & $-0.140^{\star \star *}$ & $-0.104^{* * *}$ \\
\hline & $(0.000)$ & $(0.001)$ & $(0.000)$ \\
\hline \multirow{2}{*}{ T5 } & $-0.128^{\star * *}$ & $-0.124^{\star * *}$ & $-0.128^{\star * *}$ \\
\hline & $(0.000)$ & $(0.003)$ & $(0.000)$ \\
\hline \multirow{2}{*}{ T6 } & $-0.071^{* * *}$ & $-0.105^{\star *}$ & $-0.059^{* \star}$ \\
\hline & $(0.001)$ & $(0.015)$ & (0.018) \\
\hline \multirow{2}{*}{ male } & $0.077^{\star * *}$ & $0.118^{\star \star *}$ & 0.043 \\
\hline & (0.001) & (0.001) & $(0.176)$ \\
\hline \multirow{2}{*}{ T3 $\times$ male } & 0.017 & 0.021 & -0.004 \\
\hline & $(0.663)$ & $(0.726)$ & $(0.940)$ \\
\hline \multirow{2}{*}{$\mathrm{T} 4 \times$ male } & 0.064 & $0.130^{* *}$ & -0.019 \\
\hline & $(0.109)$ & $(0.033)$ & $(0.753)$ \\
\hline \multirow{2}{*}{$\mathrm{T} 5 \times$ male } & 0.012 & 0.001 & 0.023 \\
\hline & $(0.773)$ & $(0.981)$ & $(0.694)$ \\
\hline \multirow{2}{*}{ T6 $\times$ male } & 0.016 & 0.036 & 0.019 \\
\hline & $(0.687)$ & $(0.562)$ & $(0.739)$ \\
\hline \multirow{2}{*}{ Job experience } & $-0.057^{\star \star *}$ & $-0.040^{*}$ & $-0.067^{* \star *}$ \\
\hline & $(0.000)$ & $(0.076)$ & $(0.000)$ \\
\hline \multirow{2}{*}{ Education } & $0.026^{* * *}$ & $0.033^{* * *}$ & $0.023^{* * *}$ \\
\hline & $(0.000)$ & (0.001) & $(0.001)$ \\
\hline \multirow{2}{*}{ Median wage } & -0.036 & -0.047 & -0.023 \\
\hline & $(0.110)$ & $(0.203)$ & $(0.411)$ \\
\hline Male job & $0.051^{* * *}$ & & \\
\hline advertisement? & $(0.000)$ & & \\
\hline \multirow{2}{*}{$\begin{array}{l}\text { Short application } \\
\text { questionnaire? }\end{array}$} & -0.007 & -0.123 & 0.087 \\
\hline & (0.909) & $(0.211)$ & $(0.288)$ \\
\hline City fixed effects? & yes & yes & yes \\
\hline $\mathrm{N}$ & 6070 & 2269 & 3801 \\
\hline
\end{tabular}

Notes: ${ }^{* * *} p<0.01,{ }^{* *} p<0.05,{ }^{*} p<0.1$. Coefficients present average marginal effect, i.e. differences in application probabilities. Omitted category $=\mathrm{w}$ omen in T1\&T2. P-values in parenthesis. Robust standard errors used. Male $=0$ if subject is female. $\mathrm{T} 1 \& \mathrm{~T} 2=$ treatments $w$ ith fixed hourly $\mathrm{w}$ ages $=\$ 15 . \mathrm{T} 3=$ treatment in $w$ hich compensation depends mildly on individual relative performance. If subject underperforms hourly wage $=\$ 13.5$, if she outperforms a competitor hourly $w$ age $=\$ 16.5$. T4 $=$ treatment in $w$ hich compensation depends strongly on individual relative performance. If subject underperforms hourly wage $=\$ 12$, if she outperforms a competitor hourly wage $=\$ 18$. T5 = treatment in w hich compensation depends on relative team performance. If team underperforms hourly $w$ age $=\$ 12$, if team outperforms a competing team hourly $w$ age $=\$ 18$. T6 $=$ treatment in $w$ hich compensation depends on uncertainty, hourly w age is either $\$ 13.5$ or $\$ 16.5$. 


\section{Table C: Probability of job application, omitted category is men in T1\&T2 (logit)}

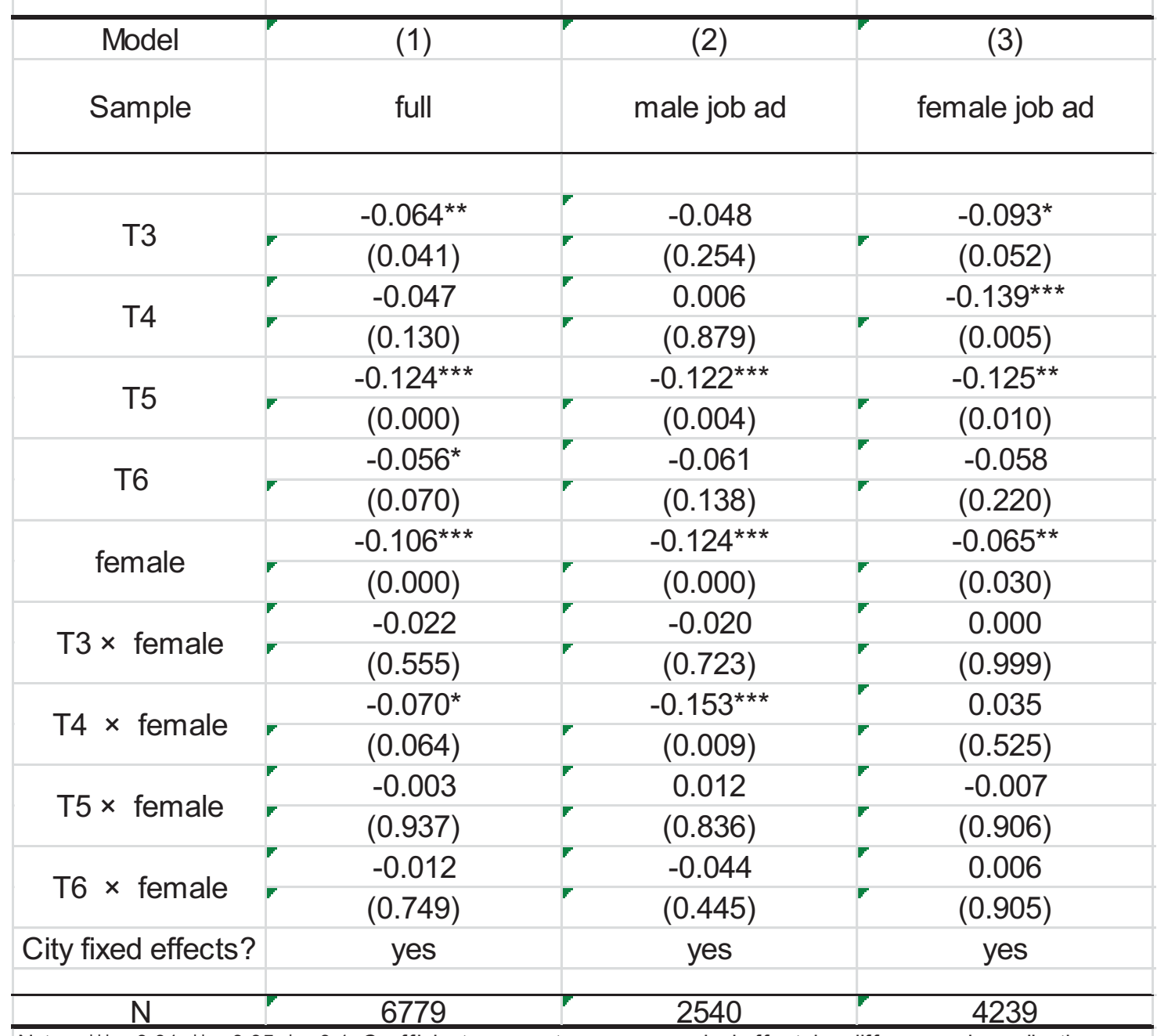

Notes: ${ }^{* * *} p<0.01,{ }^{* *} p<0.05,{ }^{*} p<0.1$. Coefficients present average marginal effect, i.e. differences in application probabilities. Omitted category $=$ men in T1\&T2. P-values in parenthesis. Robust standard errors used. Male $=0$ if subject is female. T1 \& T2 = treatments $w$ ith fixed hourly $w$ ages $=\$ 15 . T 3=$ treatment in $w$ hich compensation depends mildly on individual relative performance. If subject underperforms hourly wage $=\$ 13.5$, if she outperforms a competitor hourly wage $=\$ 16.5$. T4 $=$ treatment in w hich compensation depends strongly on individual relative performance. If subject underperforms hourly wage $=\$ 12$, if she outperforms a competitor hourly $w$ age $=\$ 18$. T5 $=$ treatment in w hich compensation depends on relative team performance. If team underperforms hourly wage $=\$ 12$, if team outperforms a competing team hourly wage $=\$ 18$. T6 $=$ treatment in w hich compensation depends on uncertainty, hourly wage is either $\$ 13.5$ or $\$ 16.5$. 


\begin{tabular}{|c|c|c|c|}
\hline Table D: Prok & $\begin{array}{r}\text { bability of jol } \\
\text { Boston, an }\end{array}$ & $\begin{array}{l}\text { cation restric } \\
\text { shington DC }\end{array}$ & $\begin{array}{l}\text { to San Francis } \\
\text { t) }\end{array}$ \\
\hline Model & (1) & (2) & (3) \\
\hline Sample & full & male job ad & female job ad \\
\hline T3 & $-0.156^{* * *}$ & -0.021 & $-0.215^{\star * *}$ \\
\hline 13 & $(0.006)$ & $(0.830)$ & $(0.001)$ \\
\hline T4 & $-0.232^{\star * *}$ & $-0.231^{* *}$ & $-0.218^{* * *}$ \\
\hline 14 & $(0.000)$ & $(0.033)$ & $(0.001)$ \\
\hline & $-0.273^{* * *}$ & $-0.231^{* *}$ & $-0.272^{* * *}$ \\
\hline 10 & $(0.000)$ & $(0.046)$ & $(0.000)$ \\
\hline T6 & $-0.127^{* *}$ & -0.087 & $-0.135^{\star *}$ \\
\hline 10 & $(0.022)$ & $(0.400)$ & $(0.029)$ \\
\hline mala & 0.024 & $0.134^{*}$ & -0.097 \\
\hline male & $(0.619)$ & $(0.072)$ & $(0.167)$ \\
\hline T3 $\times$ male & 0.095 & 0.013 & 0.072 \\
\hline 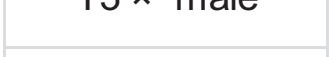 & $(0.286)$ & $(0.921)$ & $(0.598)$ \\
\hline T4 $x$ male & $0.266^{* * *}$ & $0.315^{\star *}$ & 0.159 \\
\hline $4 \times$ illate & $(0.003)$ & $(0.023)$ & $(0.230)$ \\
\hline T5 $\times$ male & $0.215^{\star *}$ & 0.175 & $0.242^{* *}$ \\
\hline 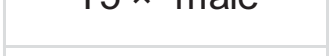 & $(0.019)$ & $(0.228)$ & $(0.048)$ \\
\hline T6 $\times$ male & $0.198^{* *}$ & 0.074 & $0.340^{* * *}$ \\
\hline $10 \times$ male & $(0.025)$ & $(0.586)$ & $(0.007)$ \\
\hline City fixed effects? & yes & yes & yes \\
\hline $\mathrm{N}$ & 1010 & 444 & 566 \\
\hline $\begin{array}{l}\text { Notes: }{ }^{* *} \mathrm{p}<0.01,{ }^{* *} \mathrm{p}<0.05 \\
\text { probabilities. Omitted cate } \\
\text { if subject is female. T1 \& } \\
\text { depends mildly on individu } \\
\text { outperforms a competitor } \\
\text { individual relative perform } \\
\text { hourly w age }=\$ 18 . T 5= \\
\text { underperforms hourly wa } \\
\text { w hich compensation dep }\end{array}$ & $\begin{array}{l}5,{ }^{*} \mathrm{p}<0.1 \text {. Coefficients } \\
\text { egory= w omen in } \mathrm{T} 1 \& \mathrm{~T} \\
\mathrm{~T} 2=\text { treatments } \mathrm{w} \text { ith fi } \\
\text { lual relative performanc } \\
\mathrm{r} \text { hourly w age }=\$ 16.5 \text {. } \\
\text { mance. If subject under } \\
\text { treatment in w hich com } \\
\text { age }=\$ 12 \text {, if team outpe } \\
\text { pends on uncertainty, } \mathrm{h}\end{array}$ & $\begin{array}{l}t \text { average marginal effect } \\
\text { ues in parenthesis. Robu } \\
\text { urly w ages }=\$ 15 \text {. T3 = tr } \\
\text { ject underperforms hour } \\
\text { eatment in w hich compen } \\
\text { s hourly wage }=\$ 12 \text {, if } \\
\text { ton depends on relative } \\
\text { a competing team hourly } \\
\text { age is either } \$ 13.5 \text { or } \$ 1\end{array}$ & $\begin{array}{l}\text { lifferences in application } \\
\text { ndard errors used. Male }= \\
\text { int in which compensation } \\
\text { ge }=\$ 13.5 \text {, if she } \\
\text { depends strongly on } \\
\text { tperforms a competitor } \\
\text { erformance. If team } \\
e=\$ 18 . T 6=\text { treatment in }\end{array}$ \\
\hline
\end{tabular}




\begin{tabular}{|c|c|c|c|}
\hline \multicolumn{4}{|c|}{$\begin{array}{r}\text { Table E: Probability of job application restricte } \\
\text { with mean hourly wage }<\$ 13 \text { (logit) }\end{array}$} \\
\hline Model & (1) & (2) & (3) \\
\hline Sample & full & male job ad & female job ad \\
\hline \multirow{2}{*}{ T3 } & $-0.076^{* * *}$ & $-0.077^{*}$ & $-0.074^{* * *}$ \\
\hline & $(0.001)$ & $(0.070)$ & $(0.005)$ \\
\hline \multirow{2}{*}{$\mathrm{T} 4$} & $-0.100^{* * *}$ & $-0.133^{* * *}$ & $-0.086^{* * *}$ \\
\hline & $(0.000)$ & $(0.003)$ & $(0.001)$ \\
\hline \multirow{2}{*}{ T5 } & $-0.108^{* * *}$ & $-0.094^{* *}$ & $-0.112^{* * *}$ \\
\hline & $(0.000)$ & $(0.027)$ & $(0.000)$ \\
\hline \multirow{2}{*}{ T6 } & $-0.058^{* * *}$ & $-0.108^{* *}$ & -0.038 \\
\hline & $(0.010)$ & $(0.016)$ & $(0.139)$ \\
\hline \multirow{2}{*}{ male } & $0.121^{* \star *}$ & $0.123^{* * *}$ & $0.095^{* * *}$ \\
\hline & $(0.000)$ & $(0.001)$ & $(0.004)$ \\
\hline \multirow{2}{*}{$\mathrm{T} 3 \times$ male } & 0.011 & 0.019 & -0.007 \\
\hline & $(0.800)$ & $(0.766)$ & $(0.902)$ \\
\hline \multirow{2}{*}{$\mathrm{T} 4 \times$ male } & 0.032 & $0.119^{*}$ & -0.069 \\
\hline & $(0.438)$ & $(0.066)$ & $(0.254)$ \\
\hline \multirow{2}{*}{ T5 $\times$ male } & -0.034 & -0.047 & -0.033 \\
\hline & $(0.431)$ & $(0.471)$ & $(0.594)$ \\
\hline \multirow{2}{*}{ T6 $\times$ male } & -0.026 & 0.035 & -0.071 \\
\hline & $(0.527)$ & $(0.586)$ & $(0.225)$ \\
\hline City fixed effects? & yes & yes & yes \\
\hline $\mathrm{N}$ & 5769 & 2096 & 3673 \\
\hline \multicolumn{4}{|c|}{ 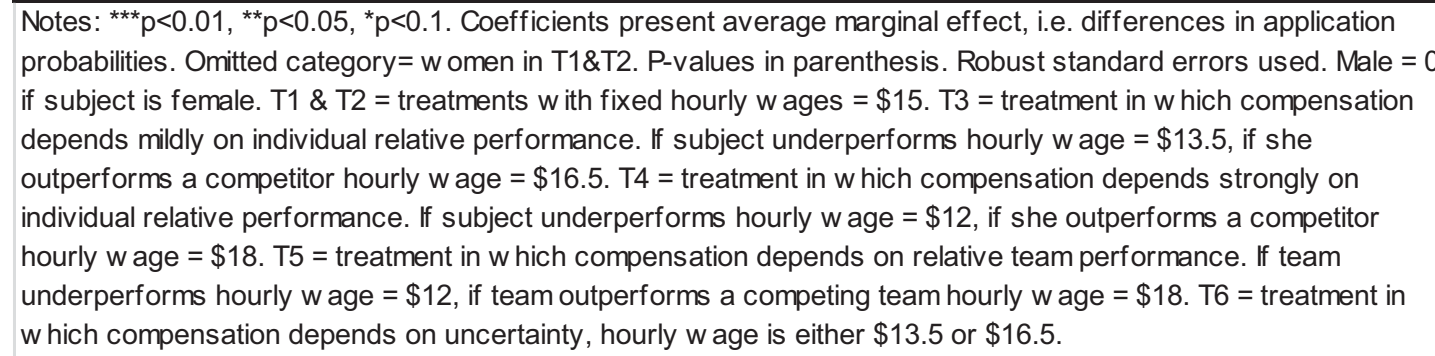 } \\
\hline
\end{tabular}




\begin{tabular}{|c|c|c|}
\hline \multicolumn{3}{|c|}{ Table F: Rating of applications (logit) } \\
\hline Model & (1) & $(2)$ \\
\hline Dependent Variable & Ability to perform job & Applicants confidence \\
\hline \multirow{2}{*}{ T3 } & 0.042 & 0.024 \\
\hline & $(0.239)$ & $(0.497)$ \\
\hline \multirow{2}{*}{ T4 } & $-0.085^{* *}$ & -0.020 \\
\hline & $(0.024)$ & $(0.511)$ \\
\hline \multirow{2}{*}{ female } & -0.044 & 0.004 \\
\hline & $(0.139)$ & $(0.873)$ \\
\hline \multirow{2}{*}{ T3 $\times$ female } & 0.017 & $-0.117^{* * *}$ \\
\hline & $(0.749)$ & $(0.010)$ \\
\hline \multirow{2}{*}{ T4 $\times$ female } & $0.172^{\star * *}$ & 0.036 \\
\hline & $(0.001)$ & $(0.429)$ \\
\hline \multirow{2}{*}{ confidence } & $0.229 * * *$ & \\
\hline & $(0.000)$ & \\
\hline \multirow{2}{*}{ ability } & & $0.191^{* * *}$ \\
\hline & & $(0.000)$ \\
\hline Rater fixed effects? & yes & yes \\
\hline $\mathrm{N}$ & 1600 & 1600 \\
\hline \multicolumn{3}{|c|}{$\begin{array}{l}\text { Notes: }{ }^{* * *} p<0.01,{ }^{* *} p<0.05,{ }^{*} p<0.1 \text {. Coefficients present average marginal effect, i.e. } \\
\text { differences in the probability rater judges applicant to be able to perform task (model } 1 \text { ) } \\
\text { or that applicant perceives herself as confident (model } 2 \text { ). Omitted category= men in } \\
\text { T1\&T2. P-values in parenthesis. Robust standard errors used. Male }=1 \text { if subject is } \\
\text { male, } 0=\text { subject is female. } \text { T1 \& T2 = treatments with fixed wages and hourly wage = } \\
\$ 15 . T 3=\text { treatment in which compensation depends on individual relative performance. } \\
\text { If subject underperforms hourly wage }=\$ 13.5 \text {, if she outperforms a competitor hourly } \\
\text { wage }=\$ 16.5 . \text { T } 4=\text { treatment in which compensation depends on individual relative } \\
\text { performance. If subject underperforms hourly wage }=\$ 12 \text {, if she outperforms a } \\
\text { competitor hourly wage }=\$ 18 . \text { Confidence: } 0=\text { not confident, } 1=\text { somewhat } \\
\text { confident, } 2=\text { confident, } 3=\text { very confident. Ability: } 0=\text { not able to perform job, } 1= \\
\text { somewhat able, } 2=\text { able, } 3=\text { very able. }\end{array}$} \\
\hline
\end{tabular}



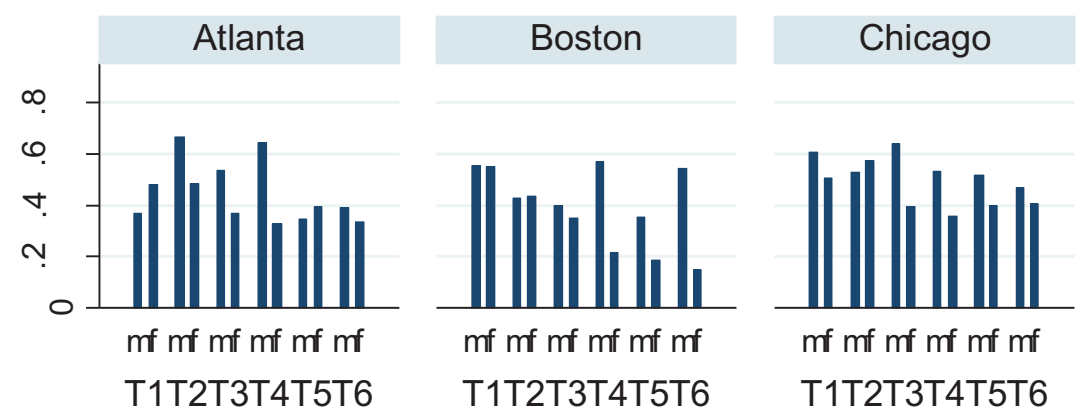

Washington DC
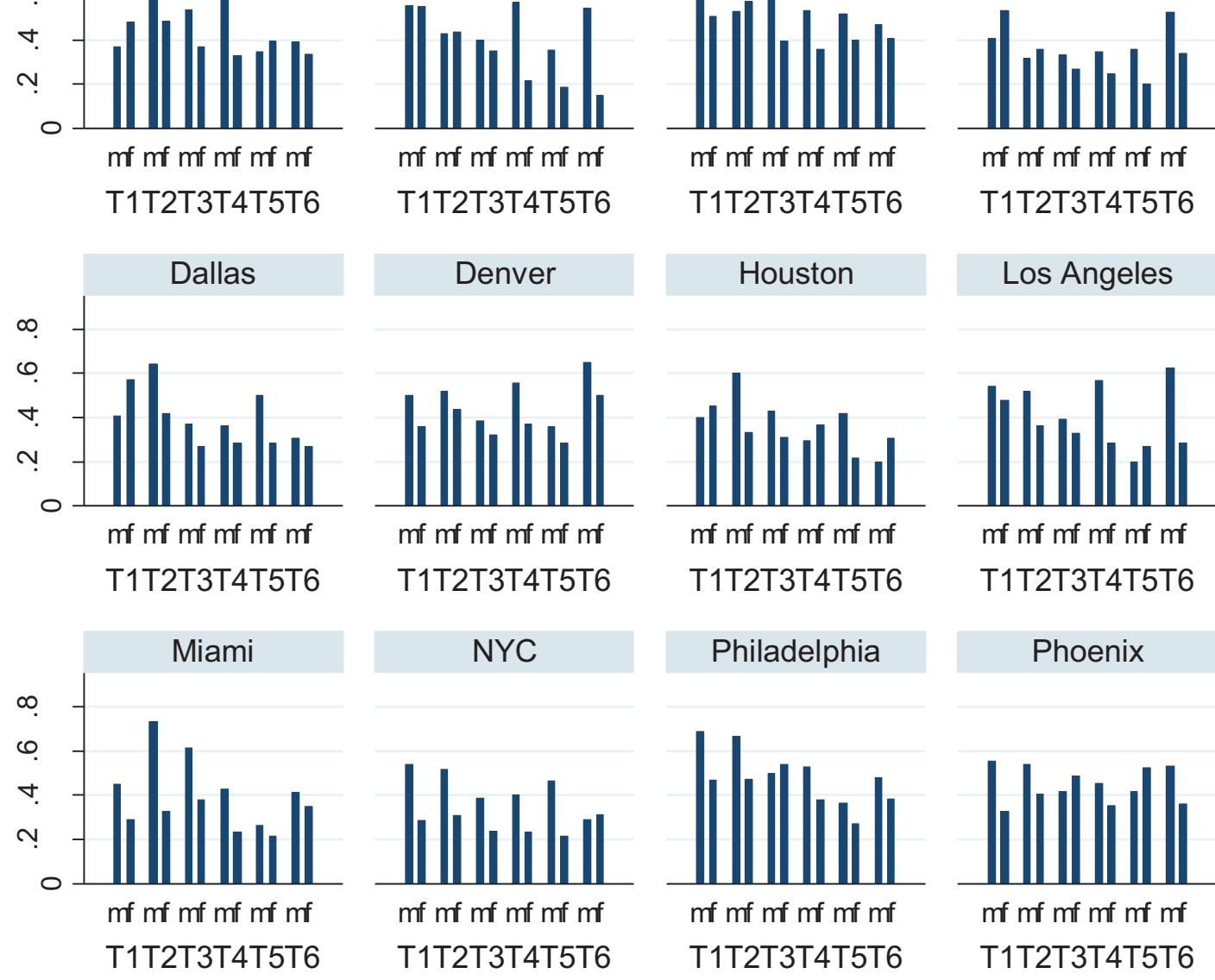

$\mathrm{mf} \mathrm{mf} \mathrm{mf} \mathrm{mf} \mathrm{mf} \mathrm{mf}$

T1T2T3T4T5T6

Los Angeles
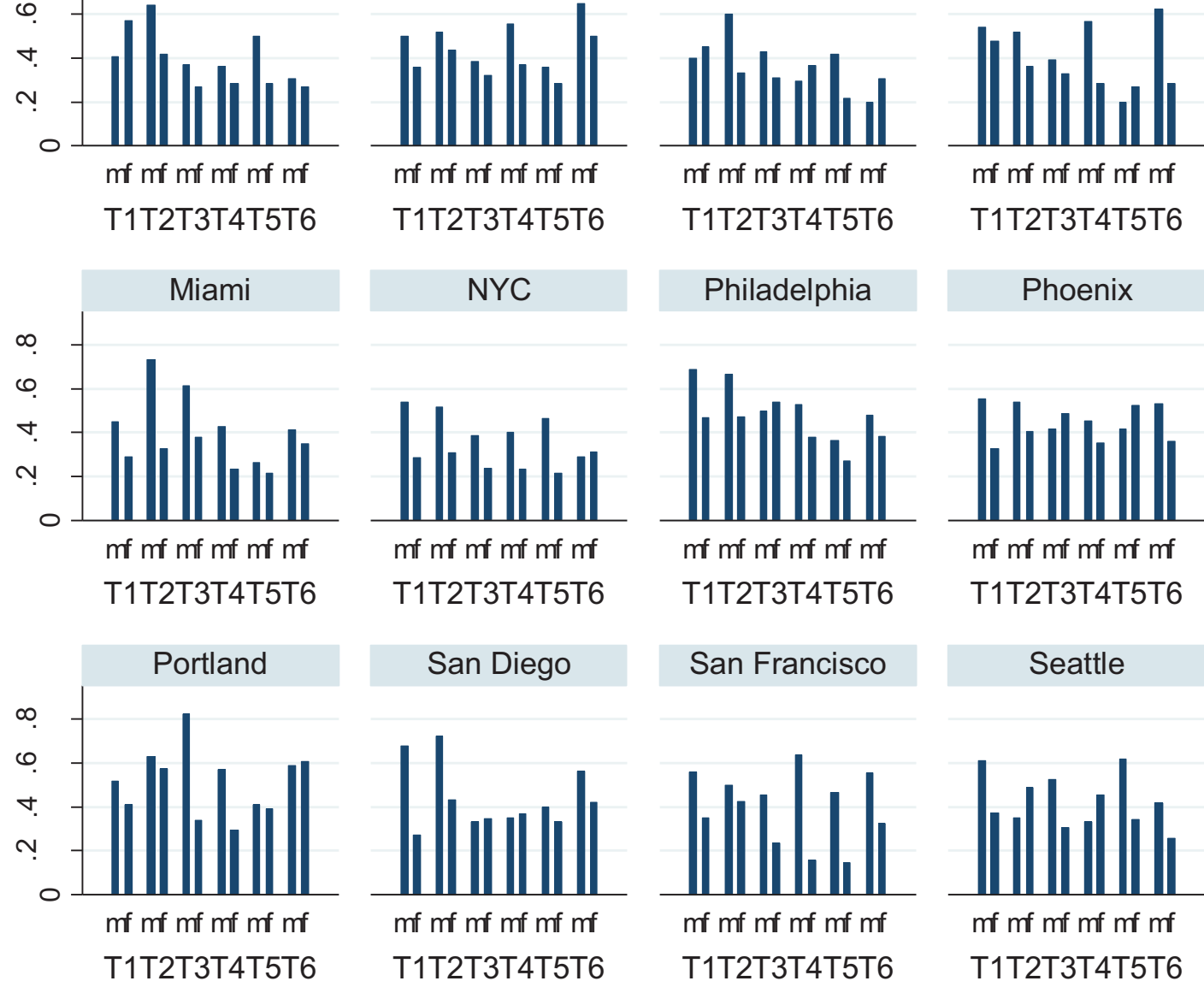

Phoenix

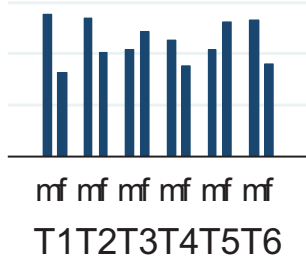

\section{Seattle}

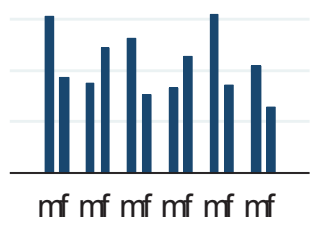

T1T2T3T4T5T6

Figure A: Application patterns on city level.

Notes: $\mathrm{m}=$ male, $\mathrm{f}=$ female. $\mathrm{T} 1 \& \mathrm{~T} 2=$ fixed wages either team or no team work, $\mathrm{T} 3=$ base wage $+22 \%$ bonus depending on individual relative performance, T4= base wage $+50 \%$ bonus depending on individual relative performance, $\mathrm{T} 5+$ base wage $+50 \%$ bonus depending on team relative performance, $\mathrm{T} 6=$ base wage $+22 \%$ bonus depending on uncertainty. 


\section{REFERENCES}

Akerlof, George A. and Kranton, Rachel E. 2000. "Economics and Identity." Quarterly Journal of Economics, 115(3): 715-753.

Altonji, Joseph G., and Rebecca Blank. 1999. "Race and Gender in the Labor Market." In Handbook of Labor Economics, Vol. 3C, eds. O. Ashenfelter, and D. Card, 3144-3259. Amsterdam: Elsevier Science.

Balafoutas, Loukas and Matthias Sutter. 2010. "Gender, Competition and the Efficiency of Policy Intervention.” Working Papers in Economics 450, Göteborg University, Department of Economics.

Barber, Bret M. and Terrance Odean. 2001. "Boys Will be Boys: Gender, Overconfidence, and Common Stock Investment." Quarterly Journal of Economics, 116(1): 261-292.

Bertrand, Marianne, and Kevin F. Hallock. 2001. "The Gender Gap in Top Corporate Jobs." Industrial and Labor Relations Review, 55(1): 3-21.

Blau, Francine, and Lawrence M. Kahn. 2000. "Gender Differences in Pay." Journal of Economic Perspectives, 14(4): 75-99.

Bureau of Labor Statistics Employment and Earnings, January 2010, Vol. 57, No. 1. Available online: http://www.bls.gov/opub/ee/empearn201001.pdf

Cason, Timothy N.; Masters, William A. and Sheremeta, oman M. 2010. "Entry into Winner-Take-All and Proportional-Prize Contests: An Experimental Study," Journal of Public Economics, 94(9-10): 604-611.

Chiappori, Pierre-Andre and Bernard Salanié. 2003. "Testing Contract Theory: A Survey of Some Recent Work." In Advances in Economics and Econometrics: Theory and Application, Eighth World Congress (Econometric Society Monographs), eds. M. Dewatripont, L. Hansen, and P. Turnovsky, 115-149. Cambridge: Cambridge University Press.

Dohmen, Thomas and Falk, Armin. Forthcoming. "Performance Pay and Multidimensional Sorting - Productivity, Preferences and Gender." American Economic Review.

Gabriel, Paul E. and Susanne Schmidtz. 2007. "Gender Differences in Occupational Distributions Among Workers." Monthly Labor Review, 130(6): 19-24.

Galor, Oded, and David N. Weil. 1996. "The Gender Gap, Fertility, and Growth." American Economic Review, 86(3): 374-387.

Gneezy, Uri, Kenneth L. Leonard and John A. List. 2009. "Gender Differences in Competition: Evidence from a Matrilineal and a Patriarchal Society." Econometrica, 77(3): 909-931. 
Gneezy, Uri, Muriel Niederle and Aldo Rustichini. 2003. "Performance in Competitive Environments: Gender Differences." Quarterly Journal of Economics, 118(3): 1049_ 1074.

Goldin, Claudia. 1990. Understanding the Gender Gap: An Economic History of American Women, New York: Oxford University Press.

Goldin, Claudia, and Cecilia Rouse. 2000. "Orchestrating Impartiality: The Impact of 'Blind' Auditions on Female Musicians." American Economic Review, 90(4): 715-741.

Groves, Theodore, Yongmiao Hong, John McMillan and Barry Naughton. 1994. "Autonomy and Incentives in Chinese State Enterprises." Quarterly Journal of Economics, 109(1):183-209.

Datta Gupta, Nabanita, Anders Poulsen and Marie-Claire Villeval. 2005. "Male and Female Competitive Behavior - Experimental Evidence.” IZA Discussion Paper, No. 1833.

Harrison, Glenn and John A. List. 2004. "Field Experiments." Journal of Economic Literature, 42(4): 1009-1055.

Hart, Oliver, and Bengt Holmstrom. 1987. "The Theory of Contracts." In Advances in Economic Theory: Fifth World Congress, ed. Truman F. Bewley. Cambridge: Cambridge University Press.

Ichniowski, Casey, Kathryn Shaw and Giovanna Prennushi. 1997. "The Effects of Human Resource Management Practices on Productivity: A Study of Steel Finishing Lines." American Economic Review, 87(3): 291-313.

Jones, Derek and Takeo Kato. 1995. "The Productivity Effects of Employee Stock-Ownership Plans and Bonuses." American Economic Review, 85(3):391-414.

Lazear, Edward. 1995. Personnel Economics, Cambridge, MA: MIT Press.

Lazear, Edward. 2000. "Performance Pay and Productivity." American Economic Review, 90(5): 1346-1361.

Lemieux, Thomas, MacLeod W. Bentley, and Daniel Parent. 2009. "Performance Pay and Wage Inequality." Quarterly Journal of Economics, 124(1): 1-49.

List, John A. and Imran Rasul. 2010. "Field Experiments in Labor Economics." National Bureau of Economic Research (Cambridge, MA) Working Paper No. 16062, June 2010.

Niederle, Muriel and Lise Vesterlund. 2007. "Do Women Shy Away From Competition? Do Men Compete Too Much?” Quarterly Journal of Economics, 122(3), 1067-1101. 
Paarsch, Harry J., and Bruce Shearer. 1999. "The Response of Worker Effort to Piece Rate: Evidence from the British Columbia Tree-Planting Industry." Journal of Human Resources, 34(4): 643-667.

Prendergast, Canice. 1999. "The Provision of Incentives in Firms.” Journal of Economic Literature, 37(1): 7-63.

Salop, Joanne and Steven Salop. 1976. "Self-Selection and Turnover in the Labor Market." Quarterly Journal of Economics, 90(4): 619-627.

Spence, Michael. 1973. “Job Market Signaling.” Quarterly Journal of Economics, 87(3): 355374.

Spencer, Steven J., Claude M. Steele, and Diane M. Quinn. 1999. "Stereotype Threat and Women's Math Performance." Journal of Experimental Social Psychology, 35, 4-28. 